\title{
Perdas quantitativas e qualidade do algodão: influência do atraso na colheita e inserção do capulho na planta
}

Quantitative losses and quality of cotton: influence of delayed harvest and insertion of the boll on the plant

Pérdidas cuantitativas y calidad del algodón: influencia del retraso de la cosecha y de la inserción de la cápsula en la planta

\section{Resumo}

A colheita é um dos processos mais importantes dentro da cadeia produtiva algodoeira, sendo o período de maior exposição a intempéries climáticas, poeira e deposição de partículas de folhas e outros materiais, que podem provocar a redução da qualidade da fibra e favorecer a perda de pluma, caso a colheita seja executada com atraso. Assim, o objetivo com este estudo foi avaliar as perdas quantitativas na pré-colheita e a qualitativa da fibra, de duas cultivares de algodão (FM 944GL e TMG 81 WS), em função do atraso na colheita e da posição do capulho na planta. Mensurou-se as perdas pré-colheita em três etapas, sendo a primeira no momento considerado ideal para a colheita, seguido de duas outras etapas de colheita posteriores, configurando em atrasos. Foi realizada a coleta manual dos capulhos encontrados no solo e dispostos dentro de uma área de coleta demarcada em cada talhão, em três repetições em cada etapa. A qualidade da fibra foi determinada de acordo com a inserção do capulho na planta: terço superior, médio e inferior. As análises das características da fibra foram realizadas no Laboratório de Classificação de Fibras da COOAMI por meio do aparelho HVI. O atraso na colheita ocasionou aumento de perdas quantitativas no solo durante a pré-colheita e de partículas de impurezas na fibra, além de reduzir o alongamento, índice micronaire e grau de cor. A cultivar FM 944GL demonstrou melhor desempenho na maioria das características de qualidade da fibra e o terço superior na planta apresentou melhor qualidade.

Palavras-chave: Índice micronaire; Perdas pré-colheita; Rendimento de fibra; Resistência da fibra.

\begin{abstract}
The harvest is one of the most important processes in the cotton production chain, since it is the period of greatest exposure to bad weather, dust, and deposition of leaf particles and other materials, which can cause a reduction in fiber quality and lead to lint loss if harvesting is delayed. Thus, the objective of this study was to evaluate the quantitative pre-harvest losses and the fiber quality of two cotton cultivars (FM 944GL e TMG 81 WS), as a function of the delay in harvest and the position of the boll on the plant. The pre-harvest losses were measured in three stages, the first at the moment considered ideal for harvesting, followed by two other harvest stages later, configuring delays. The fiber quality was determined according to the insertion of the boll on the plant: upper, middle, and lower thirds. The analyses of the fiber characteristics were performed at COOAMI's Fiber Classification Laboratory using the HVI apparatus. Delayed harvesting increased quantitative losses in soil during pre-harvest and of impurity particles in the fiber, and reduced elongation, micronaire index, and color grade. The cultivar FM 944GL showed better performance in most of the fiber quality characteristics. Finally, the upper third on the plant showed better quality.
\end{abstract}

Keywords: Fiber yield; Fiber strength; Micronaire index; Preharvest losses.

\section{Resumen}

La recolección es uno de los procesos más importantes de la cadena de producción del algodón, ya que es el periodo de mayor exposición a las inclemencias del tiempo, al polvo y a la deposición de partículas de hojas y otros 
materiales, que pueden reducir la calidad de la fibra y favorecer la pérdida de pelusa si se retrasa la recolección. Así, el objetivo de este estudio fue evaluar las pérdidas cuantitativas de precosecha y las pérdidas cualitativas de la fibra de dos cultivares de algodón (FM 944GL e TMG 81 WS), en función del retraso de la cosecha y de la posición de la cápsula en la planta. Las pérdidas previas a la cosecha se midieron en tres etapas, siendo la primera en el momento considerado ideal para la cosecha, seguida de otras das etapas posteriores de cosecha, configurando retrasos. Se realizó la recolección manual de los racimos encontrados en el suelo y dispuestos dentro de un área de recolección demarcada en cada parcela, en tres repeticiones en cada etapa. La calidad de la fibra se determinó en función de la inserción de la mata en la planta: tercio superior, medio e inferior. Los análisis de las características de las fibras se realizaron en el Laboratorio de Clasificación de Fibras de la COOAMI utilizando el aparato HVI. El retraso en la cosecha aumentó las pérdidas cuantitativas en el suelo durante la precosecha y de partículas de impureza en la fibra, además de reducir el alargamiento, el índice de micronaire y el grado de color. El cultivar FM 944GL mostró un mejor rendimiento en la mayoría de las características de calidad de la fibra. Por último, el tercio superior de la planta mostró una mayor calidad.

Palabras clave: Índice de micronaire; Pérdidas previas a la cosecha; Rendimiento de la fibra; Resistencia de la fibra.

\section{Introdução}

A colheita é uma etapa importante dentro da cadeia produtiva do algodão, pois liga a lavoura ao processamento, sendo o processamento totalmente condicionado pela colheita e quando realizada de forma inadequada, pode acarretar prejuízos qualitativos e quantitativos na fibra (Ribas, 2014). O atraso na colheita pode favorecer a contaminação do algodão exposto no campo, principalmente por terra e folhas (Carvalho, 2013), e no aumento da perda natural, devido à queda das plumas sobre o solo, após a maturação fisiológica da cultura (Leite \& Nuss, 2017).

As perdas qualitativas, em função do atraso na colheita, denotam uma elevação no índice de fibras curtas e atenuação da uniformidade de comprimento no beneficiamento, outrossim, fungos e a radiação solar podem ocasionar redução da resistência da fibra (Echer et al., 2018). Ao posso que as perdas quantitativas são devido à perda de peso e queda dos capulhos (Ferronato et al., 2002).

As propriedades da fibra são essenciais na determinação da qualidade para a indústria têxtil, influenciando na comercialização e industrialização do algodão. O produtor, conhecendo seu produto, as propriedades da fibra, valor médio e dispersões, desfrutará de fundamentos para reconhecer e negociar seu produto, à medida que a indústria têxtil deterá de instruções para tomar decisões acerca da aquisição ou não dos lotes de algodão (Freire, 2015). Além disso, Lima \& Belot (2015) afirmam que para a determinação do preço da fibra, torna-se necessário informar-se sobre os valores tabelados atuais de ágio e deságio.

Inúmeros atributos estão relacionados à qualidade da fibra, entre eles destacam-se o comprimento, uniformidade, índice micronaire, resistência à ruptura, reflectância e grau de amarelo, sendo essas características consideradas como critérios comerciais globais, além de possuírem apreço nos contratos de venda (Bachelier \& Gourlot, 2018). Para mais, ADVFN (2019) afirma que os contratos de algodão são negociados basicamente na Bolsa de Mercadorias e Futuros de São Paulo (BM \& FBOVESPA) e na Bolsa de Mercadorias de Nova Iorque (ICE), destacando ainda que o algodão é uma commodity de elevado custo de produção, assim, países que aplicam um maior nível tecnológico na produção possuem maior influência na determinação do preço.

Atualmente, o estado de Mato Grosso destaca-se como o principal produtor nacional de algodão em caroço, que é uma matéria-prima importante para a indústria têxtil (Silva et al., 2019). Além disso, o cultivo do algodoeiro no estado é realizado por empresários rurais, que gerenciam a produção até o processo de beneficiamento. Cultivado em grandes áreas, com operações agrícolas mecanizadas e condições propícias de clima e solo. A maximização da terra e a busca de escala na produção, transformaram a cotonicultura em uma atividade importante no estado (Lamas \& Chitarra, 2014). Segundo a CONAB (2021), o Mato Grosso permanece na liderança no ranking nacional, com produção estimada de 1,71 milhões de toneladas de algodão em pluma na safra de 2020/2021. 
Em função da importância da cultura do algodão para o estado de Mato Grosso e da alta exigência comercial da fibra, objetivou-se com este trabalho avaliar as perdas quantitativas na pré-colheita e qualitativas da fibra de duas cultivares de algodão em função do atraso na colheita, e de acordo com a posição do capulho na planta (i) rendimento da fibra e características físicas do capulho (ii) e nota de ágio e deságio na comercialização (iii).

\section{Metodologia}

O experimento foi conduzido em propriedade agrícola localizada no município de Ipiranga do Norte - MT, sob as coordenadas geográficas de $12^{\circ} 12^{\prime 2} 25.0^{\prime \prime S}, 56^{\circ} 02^{\prime} 28.6^{\prime} \mathrm{O}$, e altitude média de 370 metros. Segundo a classificação de Köppen e Geiger (1936), o clima é classificado como Aw, ou seja, clima tropical, com alta pluviosidade no verão e seca no inverno. A região foi escolhida pelo fato de ser uma das mais produtivas no estado, representando assim parte significativa dos produtores da região.

Inicialmente fez-se o acompanhamento do cultivo do algodão de duas cultivares de algodão: FM 944GL e TMG 81 WS, cultivadas pelo sistema de espaçamento entre linhas convencional de $0,76 \mathrm{~m}$ e em sucessão ao cultivo da soja. Durante o desenvolvimento da cultura, os tratos culturais foram conduzidos pelo responsável técnico da propriedade, de acordo com as recomendações agronômicas da cultura para a região. $\mathrm{Na}$ fase de pré-colheita foi aplicado o herbicida desfolhante Tidiazurom $120 \mathrm{~g} \mathrm{~L}^{-1}$ (Dropp Ultra SC®) na dose de $350 \mathrm{~mL} \mathrm{ha}^{-1}$ (14/07), e regulador de crescimento Etefom $480 \mathrm{~g} \mathrm{~L}^{-1}$, com Ciclanilida 60 $\mathrm{g} \mathrm{L}^{-1}$ (Finish $\left.{ }^{\circledR}\right)$ na dosagem de $1,3 \mathrm{~L} \mathrm{ha}^{-1}$ (em 14/07).

As cultivares foram produzidas em talhões distintos e localizados lado a lado, sendo as cultivares FM 944GL e TMG 81 WS produzidas nos talhões 1 e 2 , respectivamente.

Antes do início das etapas de colheita, foram extraídas 15 plantas por cultivar para caracterização agronômica (Tabela 1).

Tabela 1. Média das características agronômicas das cultivares de algodão.

\begin{tabular}{lll}
\hline \multicolumn{3}{c}{ Características Agronômicas } \\
\hline Cultivar & FM 944GL & TMG 81 WS \\
Espaçamento entre linhas (m) & 0,76 & 0,76 \\
População média (plantas ha $\left.{ }^{-1}\right)$ & $117.982,5$ & $106.140,4$ \\
Altura média da planta (m) & 1,26 & 1,52 \\
Diâmetro médio do caule a 1 cm do solo & 13,88 & 17,05 \\
Diâmetro médio do caule a 15 cm do solo & 11,50 & 14,56 \\
Altura média do 1 ${ }^{\circ}$ ramo frutífero (cm) & 35,10 & 46,20 \\
Número médio de ramos frutíferos por & 12,13 & 13,00 \\
Número médio de capulhos por planta & 15,33 & 15,73 \\
Número médio de caroços por capulho & 33,00 & 31,00 \\
\hline
\end{tabular}

Fonte: Autores.

Para a demarcação dos talhões respeitou-se uma faixa de aproximadamente 10 metros, a partir da estrada utilizada para o tráfego de máquinas, evitando-se assim contaminações por poeria nos capulhos. Em ambos os talhões foi demarcado uma área de 30 x 300 m (9000 m2/cultivar) onde foram realizadas todas as coletas de amostras. Nesta área, em cada etapa, eram demarcadas aleatoriamente 3 sub-parcelas relativas a cada tipo de avaliação, seja de perdas ou para análises qualitativas. Como os talhões eram lado a lado, as coletas eram feitas num mesmo alinhamento.

De cada cultivar avaliou-se perdas de algodão em caroço e fibra no solo e variações qualitativas ao longo do tempo. As colheitas, realizadas manualmente, foram iniciadas no décimo terceiro dia após aplicação do desfolhante, e foram realizadas 
em três etapas, configurando em atrasos na colheita, visto a primeira etapa ter sido realizada de acordo com as recomendações técnicas, como sendo ideal, ou seja, no ponto em que ocorre $90 \%$ de desfolha. As datas de colheita foram: 26 de julho e 02 e 08 de agosto. Para cada etapa de colheita eram demarcadas 3 sub-parcelas aleatórias no talhão de cada cultivar, com área correspondente a $3,8 \mathrm{~m} 2$ (5 linhas de $0,76 \mathrm{~m} \times 1 \mathrm{~m})$.

Além do fator tempo, as variações qualitativas de fibra foram quantificadas em diferentes posições de inserção do capulho na planta: terço superior, médio e inferior. Para tanto, a coleta e processamento do material eram feitos de forma separada.

Os dados de perdas em função do atraso na colheita apresentam natureza quantitativa, e ainda, foram avaliadas variáveis qualitativas do algodão. Assim, todos os dados coletados foram avaliados de forma descritiva, identificando as médias encontradas em relação a variação entre cultivares, posição e tempo (durante as semanas de colheita) (Pereira et al., 2018).

\subsection{Dados climáticos durante a colheita}

Para verificação das condições climáticas foram obtidos dados de temperatura (média, máxima e mínima), umidade relativa (média, máxima e mínima) e velocidade máxima das rajadas de vento, do banco de dados do Instituto Nacional de Meteorologia (INMET, 2020). Estes dados foram coletados pela estação automática instalada no município de Sorriso - MT, com latitude $-12,33^{\circ}$, longitude $-55,43^{\circ}$, e altitude média de $380 \mathrm{~m}$. Os dados climáticos compreendem desde a data da aplicação do desfolhante em 14 de julho de 2017, até a data da última colheita em 08 de agosto de 2017.

\subsection{Teor de água da fibra do algodão em caroço e do caroço durante a colheita}

O teor de água da fibra foi determinado minutos após a colheita com a utilização do equipamento de medição portátil da marca Delmhorst, modelo C-2000. As amostras de fibras eram coletadas e encaminhadas a algodoeira Celeste, localizada em Sorriso - MT.

O teor de água do caroço foi determinado pelo método padrão da estufa com circulação forçada de ar, à temperatura de $105 \pm 3^{\circ} \mathrm{C}$, durante 24 horas, contabilizando a umidade pela perda de massa de água (Brasil, 2009).

\subsection{Perdas quantitativas e avaliação de qualidade em função do atraso na colheita}

O levantamento das perdas quantitativas na pré-colheita, em decorrência do atraso na colheita, foi realizado pela coleta manual de todo o algodão caído sobre uma área de $3,8 \mathrm{~m}^{2}$, escolhida aleatoriamente no talhão (5 linhas x 1 metro, com espaçamento de $0,76 \mathrm{~m}$ entre linhas). Realizou-se três repetições por cultivar, em cada etapa de colheita. O material colhido foi transportado para o laboratório de Pós-colheita da UFMT campus de Sinop. Após a retirada das impurezas, restos de folhas e materiais estranhos presentes na pluma, as amostras foram pesadas em balança semi-analítica para cálculo da perda por hectare. Com a massa dos capulhos coletados no solo, na área de $3,8 \mathrm{~m}^{2}$, extrapolou-se o valor para $10.000 \mathrm{~m}^{2}(1 \mathrm{ha})$, convertendo o valor de $\mathrm{g}$ ha-1 para @ ha- ${ }^{-1}$.

Foi coletado de modo manual aproximadamente $1 \mathrm{~kg}$ de algodão em pluma nas diferentes alturas da planta, sendo essas, terço superior, médio e inferior, em três repetições para cada cultivar, em cada etapa de coleta. As amostras foram acondicionadas em embalagens de polietileno e conduzidas ao laboratório de Pós-Colheita da UFMT campus de Sinop e realizado de modo manual o descaroçamento do algodão. Após o descaroçamento, a pluma foi encaminhada a um laboratório terceirizado para análises pelo HVI (High Volume Instrument) para determinar a qualidade da fibra.

Foram quantificadas as seguintes propriedades da fibra: comprimento, uniformidade, resistência, alongamento, índice micronaire, maturidade, índice de fibras curtas, índice de fiabilidade, índice de reflectância, grau de amarelecimento, grau de 
cor, número de partículas de impurezas superficiais, percentual de área ocupada pelas impurezas e grau de folha.

\subsection{Rendimento da fibra e características físicas dos capulhos}

Utilizando a mesma área demarcada para a avaliação das perdas qualitativas do algodão, foi coletado aproximadamente $1 \mathrm{~kg}$ de algodão em caroço para avaliações físicas. Os capulhos foram colhidos em três alturas da planta (terço superior, terço médio e o terço inferior da cultura) e acondicionados separadamente em sacos plásticos e encaminhados ao laboratório de Pós-Colheita da UFMT campus de Sinop.

Para determinação do rendimento de fibra foram selecionados de modo aleatório 30 capulhos que foram pesados, obtendo-se assim o peso médio de cada capulho (PC) e, após isso, realizou-se o descaroçamento para obtenção do peso da fibra (PF). Assim, a porcentagem do rendimento de fibra (RF) foi calculada pela Equação 01.

$$
\mathrm{RF}=\frac{\mathrm{PF}}{\mathrm{PC}} \times 100
$$

Quantificou-se ainda o número médio de caroços por capulho após o descaroçamento manual e o peso médio de caroços por capulho por pesagem em balança semi-analítica.

\subsection{Atribuição de notas para ágio e deságio na comercialização}

Segundo a ANAE (2018) existem cinco características qualitativas do algodão que possuem ágio e deságio na comercialização, sendo essas a resistência, índice micronaire, cor, índice de fibras curtas (SFI) e comprimento.

Por meio dos valores observados durante as coletas de algodão, em cada posição dos capulhos na planta, para cada uma das caraterísticas citadas acima, atribuiu-se notas em relação aos valores de ágio e deságio demonstrados pela ANAE (2018), o resultado foi plotado graficamente.

Para a atribuição das notas, determinou-se inicialmente o valor utilizado como base no momento da comercialização para cada uma das características, onde esse valor situa-se entre o limite mínimo sem que ocorra deságio e o valor máximo sem que ocorra ágio. Determinou-se assim notas para os valores de base, de 5 a 10. Apresentado notas inferiores a 5 referente ao deságio no momento da comercialização e superiores a 10, como sendo ágio. Características que apresentaram notas entre 5 e 10 não foram consideradas ágio ou deságio. Para calcular as notas, interpolou-se o valor verificado em cada uma das características ao longo do tempo e posição com os limites de ágio e deságio das mesmas.

\section{Resultados e Discussão}

\subsection{Dados climáticos durante a colheita}

As condições climáticas do local do experimento durante as semanas de colheita são apresentadas na Figura 1. Verifica-se que a temperatura e umidade relativa do ar para as 3 semanas de colheita, estiveram de acordo com o que ocorre normalmente na região. Trata-se da época de estação seca, sem precipitações, e caracterizada por altas temperaturas e baixas umidade relativas, o que promove rápida secagem do algodão no campo, podendo resultar em perdas quantitativas caso haja atrasos no processo de colheita.

A temperatura média ficou em torno de $25^{\circ} \mathrm{C}$, com máximas entre 35 e $37{ }^{\circ} \mathrm{C}$ e mínimas pouco abaixo de $20{ }^{\circ} \mathrm{C}$. Por se tratar da estação seca, a umidade relativa média manteve-se entre 40 e 48\%, com máximas entre 70 e $80 \%$ e, mínimas próximas a $20 \%$ que ocorrem normalmente no período diurno combinado a alta insolação, contribuindo de forma efetiva na secagem natural do algodão. Poucas oscilações importantes de temperatura e umidade relativa foram registradas no período. 
Figura 1. Temperatura e umidade relativa durante o processo de colheita do algodão. Em que: $1^{\mathrm{a}} ; 2^{\mathrm{a}}$ e $3^{\mathrm{a}}$ são as datas de colheita.

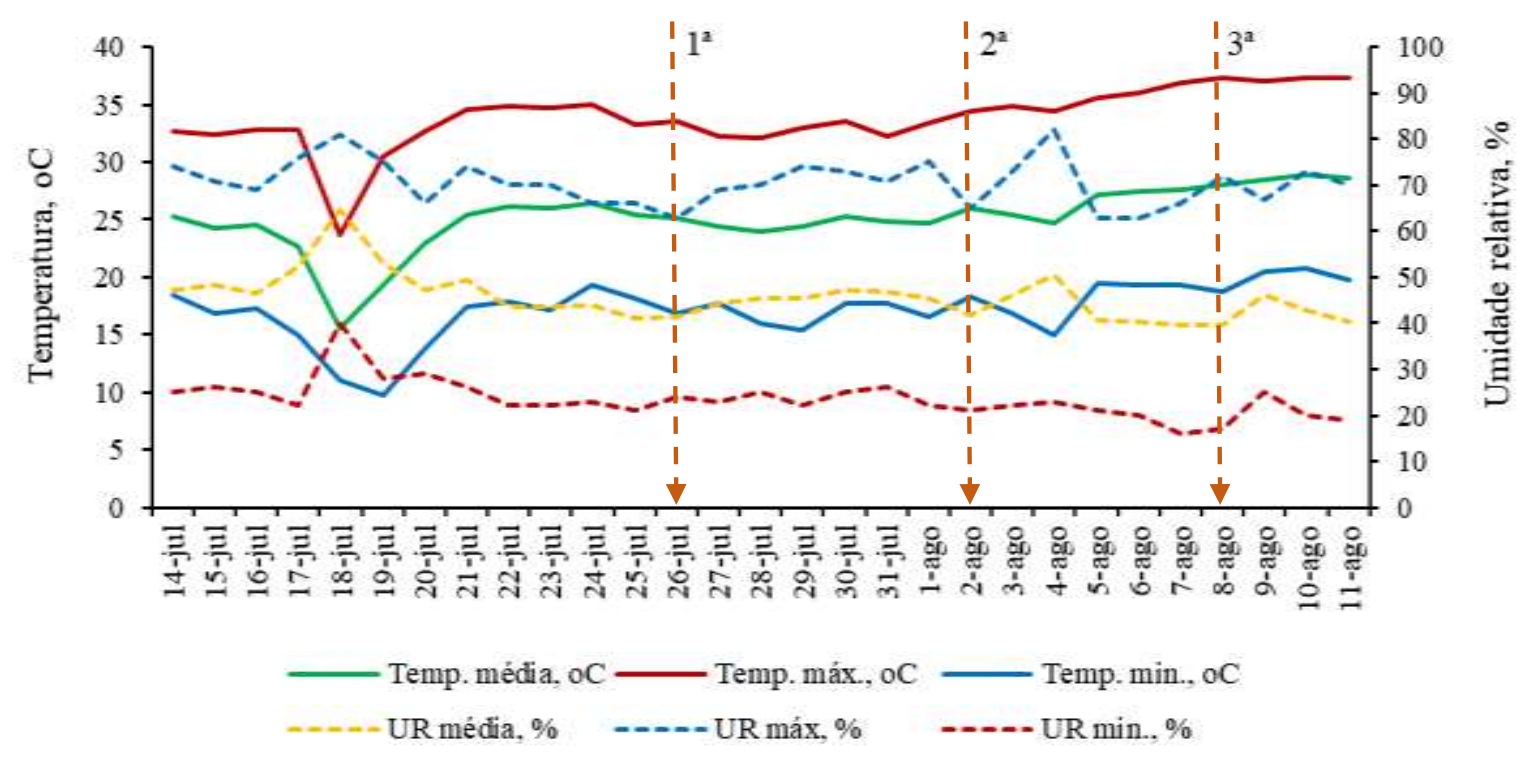

Fonte: Autores.

Ainda em relação ao clima, as variações das rajadas de vento durante o período de pré-colheita e colheita são apresentadas na Figura 2. Nota-se uma tendência de aumento de velocidade de vento do quarto dia após aplicação do desfolhante até a semana compreendida entre a $1^{\mathrm{a}}$ e $2^{\mathrm{a}}$ colheitas, reduzindo em seguida, entre a $2^{\mathrm{a}}$ e $3^{\mathrm{a}}$ semana de colheita.

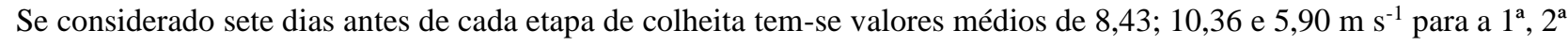
e $3^{\mathrm{a}}$ semanas de colheita, respectivamente. Em geral, as rajadas de vento oscilaram entre 14,30 e $5,10 \mathrm{~m} \mathrm{~s}^{-1}$, com média geral de $8,70 \mathrm{~m} \mathrm{~s}^{-1}$.

A análise deste fator é importante no que se refere a perdas pré-colheita, pois após desfolha química, os capulhos abertos ficam vulneráveis à ação do vento, podendo a pluma desprender-se do capulho e cair junto ao solo. 
Figura 2. Velocidade máxima da rajada de vento durante a colheita do algodão. Em que: $1^{\mathrm{a}} ; 2^{\mathrm{a}}$ e $3^{\mathrm{a}}$ são as datas de colheita.

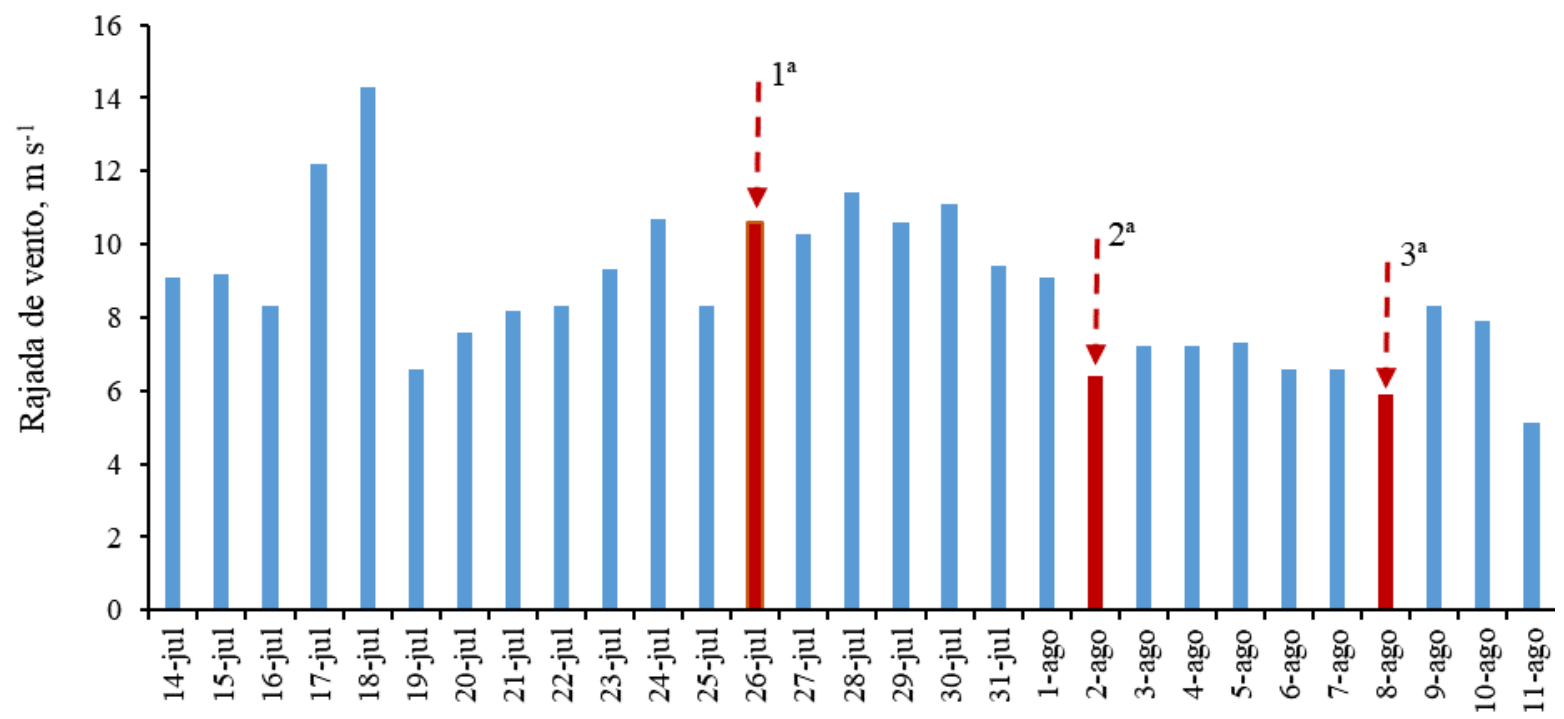

Fonte: Autores.

\subsection{Teor de água da fibra do algodão em caroço e do caroço durante a colheita}

A variação do teor de água da fibra ainda no caroço e somente do caroço em função do atraso da colheita são descritas na Figura 3. Observa-se que a cultivar FM 944GL apresentou teor de água da fibra superior quando comparada com a variedade TMG $811 \mathrm{WS}$, da primeira à última semana, e em todas as posições na planta. Em relação a umidade do caroço perceba-se que houve pouca variação entre as cultivares e as posições da planta em relação ao atraso da colheita.

A cultivar FM 944GL apresentou na $1^{\mathrm{a}}$ e a $3^{\mathrm{a}}$ semana de colheita menores valores do teor de água da fibra do algodão nas posições média e superior da planta, ao passo que na posição inferior, devido a menor incidência solar, o teor de água foi maior. $\mathrm{Na} 2^{\mathrm{a}}$ semana, verifica-se aleatoriedade do teor de água em relação as posições na planta, sendo pouco menor na posição inferior, entretanto a maior diferença entre as três posições foi de no máximo 0,5\% (b.u.).

Para a cultivar TMG 81 WS nota-se tendência de menores valores da parte intermediária para a superior na $1^{\mathrm{a}}$ e $2^{\mathrm{a}}$ semana de colheita, invertendo na $3^{\mathrm{a}}$, com maior teor de água na posição superior. A média geral, entre posições e as semanas de colheita para as cultivares FM 944GL e TMG 81 WS foi de 7,2 e 5,7\% (b.u.), respectivamente.

Em relação ao caroço, a tendência durante as colheitas, para a cultivar FM 944GL, foi a de apresentar teor de água pouco maior na posição inferior, seguida da posição média da planta, diferentemente do que foi constatado para a cultivar TMG 81 WS onde o maior teor de água foi observado na posição superior, com pouca variação entre a média e inferior. O teor de água médio do caroço foi de 6,2 e 6,1\% (b.u.), com variação máxima de 0,8 e 0,5\% (b.u.) para a, FM 944GL e a TMG 81 WS, respectivamente.

Acredita-se que a variação aleatória do teor de água, principalmente na fibra do algodão, em relação a colheita e posição na planta podem ser decorrentes da variação de arquitetura e maturação de capulhos entre plantas, ou ainda, algum fator relacionado ao clima como visto na Figura 1. 
Figura 3. Valores médios observados de teor de água do algodão em caroço e do caroço, de duas cultivares, em diferentes posições na planta e, em função do atraso na colheita. Em que: (Sup.) terço superior; (Med.) terço médio; (Inf.) terço inferior.
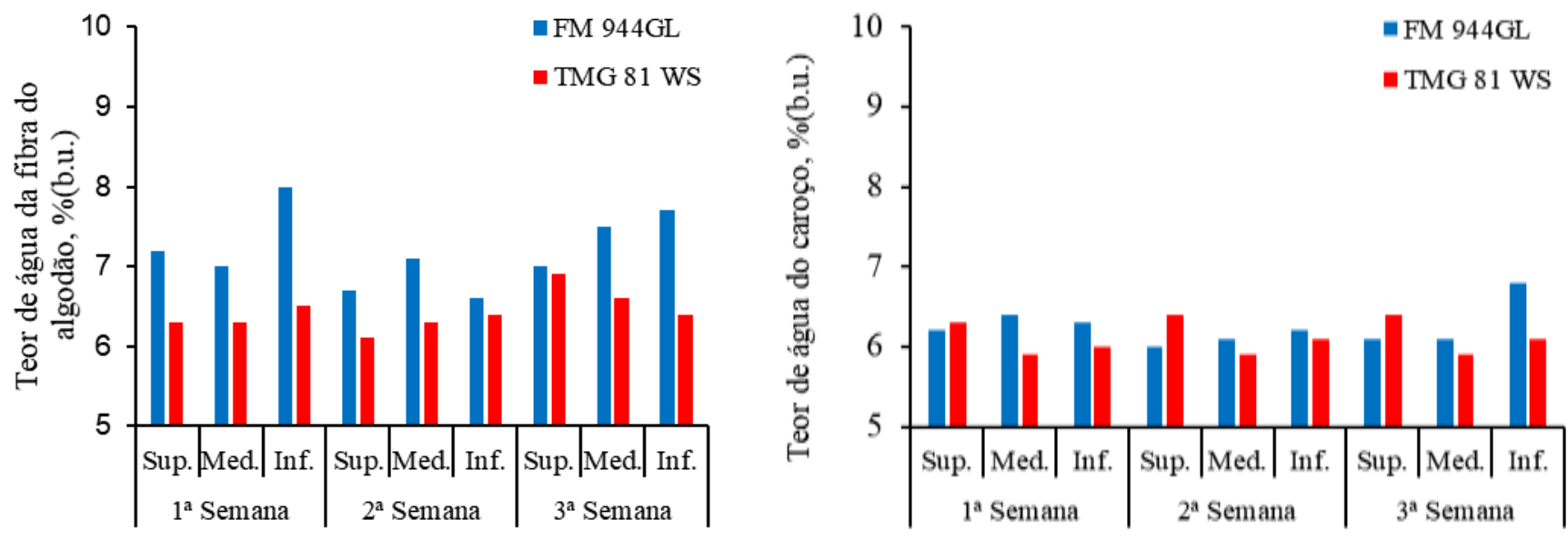

Fonte: Autores.

Segundo Mion et al. (2014), para não gerar a degradação da fibra, amarelecimento, manchas e o "encarneiramento", recomenda-se que o teor de água da fibra no momento da colheita mecânica seja inferior a 8\% (b.u.). Caso seja efetuada a colheita com teor de água superior a $16 \%$ (b.u.), mesmo que descaroçado em seguida incidirá em perdas. Corroborando com o citado por Lima et al. (2018) que ressaltam que amostras com teor de água médio entre 6,5 e 8,0\% (b.u.) apresentam melhor precisão e acurácia no momento da mensuração das propriedades físicas das fibras de algodão. Em complemento, Costa et al. (2006) afirmam que no momento da colheita mecânica é fundamental que o teor de água do algodão em caroço, não seja superior a 12\% (b.u.), e de acordo com Freire (2015), teor de água do algodão em caroço superior a 12\% (b.u.), pode resultar em acidez, consequentemente, haverá redução do poder germinativo. É desejável que o teor de água do caroço seja igual ou inferior a $10 \%$ (b.u.), caso a destinação seja para a produção de sementes, no tempo em que a destinação seja a trituração, valores menores ou iguais a $12 \%$ (b.u.) são as mais adequadas.

Diante dessas afirmações e observações, pode-se inferir que a colheita da fibra e do algodão em caroço foi realizada no momento correto, tanto para o caso da utilização do algodão para semente, quanto para industrialização. Apesar da diferença entre as cultivares, o teor de água encontra-se dentro da faixa indicada para a colheita, não ocasionando perdas neste processo. Além disso, a época de colheita do algodão no estado de Mato Grosso coincide com a estação seca, com altas temperaturas e baixa umidade relativa (Figura 1), o que favorece a secagem natural, possibilitando a colheita dentro da faixa de teor de água considerado como ideal.

\subsection{Avaliação de perdas pré-colheita e de qualidade do algodão em função do atraso na colheita}

Na Figura 4 são mencionadas as perdas quantitativas no solo, durante a pré-colheita, do algodão em caroço e de fibra em função do atraso na colheita. Perceba-se elevada perda no algodão em caroço e de fibra a partir da $2^{\mathrm{a}}$ e $3^{\mathrm{a}}$ semana de colheita para ambas as cultivares, possivelmente ocasionada pela ação dos ventos que foram mais fortes entre a $1^{\mathrm{a}} \mathrm{e} 2^{\mathrm{a}}$ semanas (Figura 2), além do fator tempo, ou seja, quanto mais tempo o produto permanecer no campo, maior a probabilidade de perdas, que são cumulativas. De modo geral, a cultivar FM 944GL atingiu valores maiores perdas durante o atraso da colheita do que a cultivar TMG 81 WS, com médias gerais de perdas do algodão em caroço de 2,81 e 3,49 @ ha-1 e da fibra de 1,25 e 1,53 @ ha 1 , respectivamente.

Para o algodão em caroço, nota-se que na $1^{\mathrm{a}}$ semana, considerada como ponto ideal para a colheita, as perdas são de aproximadamente 1,72@ ha ${ }^{-1}( \pm 0,03)$ para ambas as cultivares. Na semana seguinte houve um aumento para 2,77 e 4,03 @ 
ha $^{-1}$, respectivamente para as cultivares FM 944GL e TMG 81 WS, aumento correspondente a 58,29 e 124,00 \% em relação a $1^{\text {a }}$ semana. Na $3^{\mathrm{a}}$ semana de colheita, as perdas foram de 3,92 e 4,74 @ ha-1 para as cultivares FM 944GL e TMG 81 WS, resultando em um aumento de 138,46 e $180,47 \%$, respectivamente, quando comparado a perda encontrada na $1^{\text {a }}$ semana. A perda média geral do algodão em caroço foi de 2,81@ ha ${ }^{-1}$ para a cultivar FM 944GL e de 3,49 @ ha-1 para a cultivar TMG 81 WS.

Em relação as perdas de fibra, na $1^{\mathrm{a}}$ semana, ambas as cultivares tiveram perdas semelhantes, com cerca de 0,83 e 0,74 @ ha-1 para as variedades de FM 944GL e TMG 81 WS, respectivamente. Na $2^{\mathrm{a}}$ semana houve um acréscimo de 44,58 e 107,23\% de perda de fibra das cultivares FM 944GL e TMG 81 WS, alcançando médias de 1,20 e 1,81 @ ha ${ }^{-1}$, respectivamente. Na última semana, obteve-se médias de 1,72 e 2,03 @ ha-1 para as cultivares FM 944GL e TMG 81 WS. A diferença percentual de perdas da $1^{\text {a }}$ para a última semana foi de 144,59 e 174,32 \%, respectivamente, para as cultivares FM 944GL e TMG 81 WS.

No trabalho de Viotto et al. (2018), avaliando as perdas na colheita do algodão em função da velocidade da colhedora, observaram-se que as perdas no solo de algodão em caroço na pré-colheita foi de 2,17 e 0,54 @ ha-1 para as cultivares FM 951LL e FM 975WS, respectivamente. Enquanto que na pesquisa de Silva \& Cassia (2011), com o objetivo de quantificar as perdas do algodão em caroço, encontraram perdas no solo com médias de 6,51; 5,06 e 10,97 @ ha-1 respectivamente, em três propriedades no estado de Goiás. Além disso, os autores afirmaram que as perdas no solo nas três propriedades estudadas sobressaíram-se sobre as perdas na planta, representando em média 59\% das perdas totais.

No presente estudo, verifica-se médias de perdas inferiores quando confrontado com o estudo apresentado por Silva \& Cassia (2011), porém, valores médios superiores aos observados por Viotto et al. (2018). O atraso na colheita proporcionou perdas consideráveis de algodão (pluma mais caroço), ficando claro que, quanto maior o tempo de exposição do produto no campo, maiores serão as perdas, e consequentemente maiores os prejuízos.

Figura 4. Valores médios observados de perdas pré-colheita de algodão em caroço e de fibra, de duas cultivares, em função do atraso na colheita.

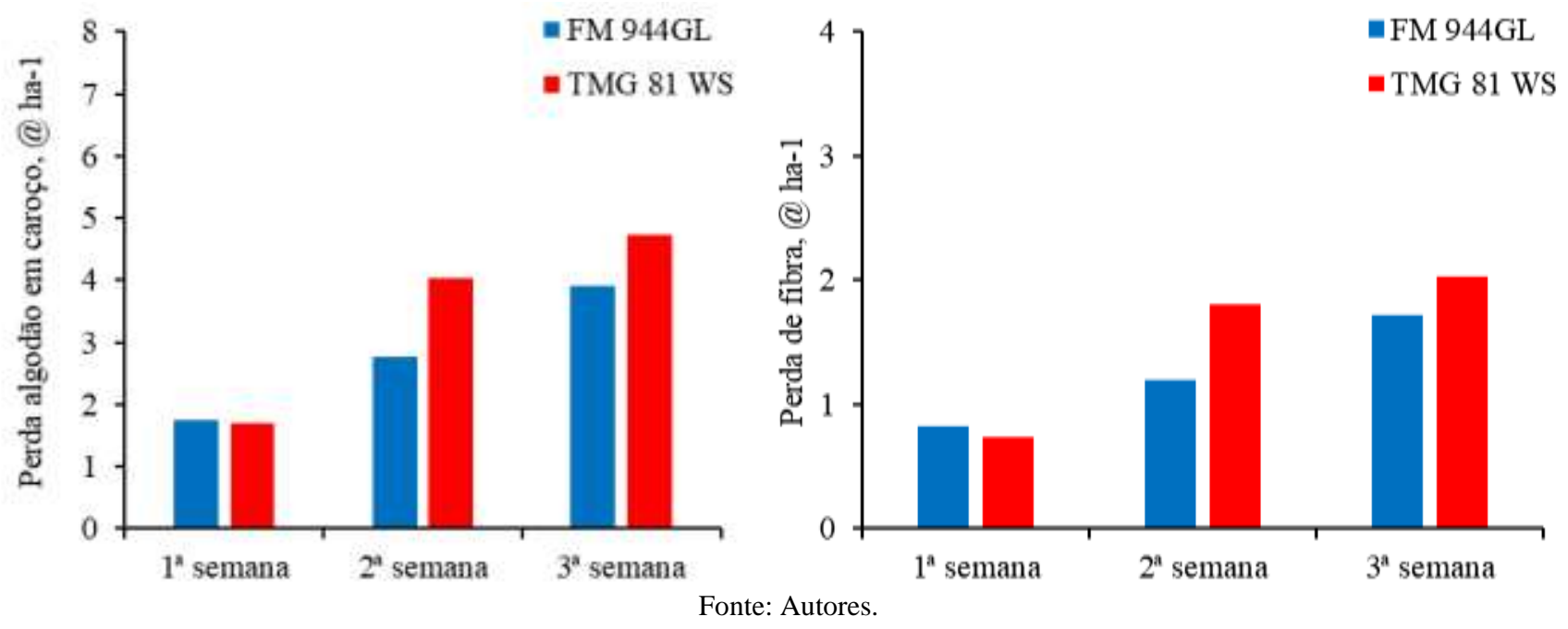

A variação do comprimento, uniformidade, resistência e alongamento da fibra do algodão em função do atraso na colheita são observadas na Tabela 2. O atraso na colheita não promoveu alterações sobre o comprimento e a uniformidade da fibra do algodão, ambas as cultivares apresentaram valores similares para essas características, com médias gerais de 31,43 mm e $86,29 \%$, respectivamente. 
Entre as semanas de colheita, verifica-se uma tendência de melhores valores de comprimento e uniformidade de fibra na $1^{\mathrm{a}}$ e $3^{\mathrm{a}}$ semana para ambas as cultivares. É provável que as diferenças observadas durante as semanas de coleta sejam em função da heterogeneidade entre plantas no talhão e na área em geral. Possivelmente no ponto de coleta do material na $2^{\mathrm{a}}$ semana, em que se procedia praticamente na mesma altura dos talhões (mesmo alinhamento) para ambas as cultivares, houvesse alguma característica de fertilidade do solo que tenha influenciado no desenvolvimento das plantas e proporcionado menor desenvolvimento das fibras, ou então, que houvesse naquele local outros problemas, como maior incidência de pragas ou doenças.

Em relação a posição na planta, no terço inferior obteve-se valores de comprimento de fibra superiores para as duas cultivares, seguido do terço médio e superior. Para a uniformidade, os terços médio e inferior tenderam a apresentar as melhores médias. Os valores médios obtidos foram similares aos apresentados por Bélot et al. (2017), avaliando a qualidade HVI da fibra de talhões comerciais para as mesmas cultivares, verificaram comprimento médio da fibra de 30,07 e 28,86 mm e, uniformidade de 82,94 e 83,10\% para as cultivares FM 944GL e TMG 81 WS, respectivamente.

Resultados semelhantes foram encontrados por Silva Filho et al. (2017) que realizaram estudo com cultivares de algodoeiro no cerrado da Bahia, obtiveram valores médios de 30,4 e 29,6 mm no comprimento e 84,6 e 84,7\% na uniformidade da fibra para as cultivares FM 944GL e TMG 81 WS, respectivamente. Assim como, no trabalho de Santos et al. (2016), avaliando a qualidade da fibra do algodoeiro fertirrigado, encontraram médias de 30,03 $\mathrm{mm}$ e 84,8\% para o comprimento e uniformidade, respectivamente, da cultivar NuOPAL BG RR.

O comprimento de fibras é considerado ideal para a indústria têxtil quando se encontra em valores acima de $30 \mathrm{~mm}$ (Santana, 2004; Carvalho et al., 2015), enquanto que para a uniformidade da fibra, o mercado têxtil exige acima de 80,0\% (Santana et al., 2008). Segundo a Instrução Normativa $n^{\circ} 63$ (Brasil, 2002), o comprimento e a uniformidade da fibra encontrados neste estudo são classificados como comprimento longo e uniformidade muito alta, ou seja, estando dentro da faixa ideal para a indústria têxtil, independente das fontes de variação estudadas.

$\mathrm{O}$ atraso na colheita não descaracterizou a resistência da fibra durante o tempo, no entanto, o mesmo não aconteceu para o alongamento da fibra. De modo geral, as cultivares a FM 944GL e TMG 81 WS apresentaram valores similares, com médias gerais de 30,37 e 30,23 g tex ${ }^{-1}$ para resistência, e de 6,79 e 6,86\% no alongamento, respectivamente.

No decorrer das semanas, a resistência teve aumento nas médias para a cultivar TMG 81 WS, enquanto que a FM 944GL tem-se o pico da resistência na $2^{a}$ semana de colheita. Para o alongamento da fibra não houve oscilações consideradas relevantes em ambas as cultivares. Quando analisado a posição na planta, verifica-se tendência de maior resistência no terço superior, seguido do terço médio e inferior, entretanto, no alongamento da fibra, observa-se percentuais maiores no terço inferior, acompanho dos terços médio e superior.

Em outras pesquisas com fibra de algodão as médias de resistência e alongamento foram semelhantes, corroborando com os dados apresentados. Farias et al. (2015) avaliando as cultivares de algodoeiro herbáceo na região de Sinop - MT, verificaram valores médios de resistência e alongamento da fibra de 28 e $27,7 \mathrm{~g}^{-1} \mathrm{x}^{-1}$ e 5,43 e 5,79\% para as cultivares FM 944GL e TMG $81 \mathrm{WS}$, respectivamente. Morello et al. (2015), em ensaio realizado no cerrado baiano com as mesmas cultivares deste estudo, alcançaram médias de resistência de fibra de 32,3 a $31,2 \mathrm{~g} \mathrm{tex}^{-1}$ e alongamento de 6,48 a 7,33\%, respectivamente.

Santana (2008) cita que o valor mínimo de resistência da fibra requerido pela indústria têxtil é de $29,0 \mathrm{~g} \mathrm{tex}^{-1}$, no sentido de minimizar a quebra dos fios durante o processamento do algodão, enquanto que o alongamento da fibra desejado pela indústria têxtil deve ser superior a 7\%. De modo geral, a resistência verificada neste estudo se classifica como resistente, segundo a Instrução Normativa $\mathrm{n}^{\circ} 63$ (Brasil, 2002). O alongamento da fibra apresentou valores pouco abaixo do desejado, entretanto, verificou-se que é uma característica pouco influenciada pela posição do capulho na planta e por atrasos na colheita. 
Tabela 2. Valores médios observados do comprimento, uniformidade, resistência e alongamento da fibra de duas cultivares de algodão, em diferentes posições na planta e, em função do atraso na colheita.

\begin{tabular}{|c|c|c|c|c|c|c|}
\hline \multirow{2}{*}{ Comprimento da fibra (mm) } & \multicolumn{2}{|c|}{$1^{\text {a }}$ Semana } & \multicolumn{2}{|c|}{$2^{a}$ Semana } & \multicolumn{2}{|c|}{$3^{\text {a }}$ Semana } \\
\hline & FM 944GL & TMG $81 \mathrm{WS}$ & FM 944GL & TMG $81 \mathrm{WS}$ & FM 944GL & TMG 81 WS \\
\hline Terço Superior & 31,20 & 30,70 & 31,00 & 31,20 & 31,80 & 29,70 \\
\hline Terço Médio & 32,50 & 31,20 & 30,00 & 31,80 & 31,50 & 31,20 \\
\hline Terço Inferior & 32,80 & 32,00 & 32,00 & 31,20 & 31,80 & 32,30 \\
\hline Média & 32,17 & 31,30 & 31,00 & 31,40 & 31,70 & 31,10 \\
\hline \multirow{2}{*}{ Uniformidade da fibra $(\%)$} & \multicolumn{2}{|c|}{$1^{\mathrm{a}}$ Semana } & \multicolumn{2}{|c|}{$2^{\mathrm{a}}$ Semana } & \multicolumn{2}{|c|}{$3^{\text {a }}$ Semana } \\
\hline & FM 944 GL & TMG $81 \mathrm{WS}$ & FM 944GL & TMG $81 \mathrm{WS}$ & FM 944GL & TMG $81 \mathrm{WS}$ \\
\hline Terço Superior & 85,90 & 86,70 & 86,20 & 85,80 & 86,60 & 85,60 \\
\hline Terço Médio & 87,10 & 85,80 & 85,70 & 86,20 & 86,40 & 86,90 \\
\hline Terço Inferior & 86,80 & 87,40 & 84,80 & 85,30 & 86,80 & 87,10 \\
\hline Média & 86,60 & 86,60 & 85,60 & 85,80 & 86,60 & 86,50 \\
\hline \multirow{2}{*}{ Resistência da fibra $\left(\mathrm{g} \mathrm{tex}^{-1}\right)$} & \multicolumn{2}{|c|}{$1^{\text {a }}$ Semana } & \multicolumn{2}{|c|}{$2^{\mathrm{a}}$ Semana } & \multicolumn{2}{|c|}{$3^{\text {a }}$ Semana } \\
\hline & FM 944GL & TMG $81 \mathrm{WS}$ & FM 944GL & TMG $81 \mathrm{WS}$ & FM 944GL & TMG $81 \mathrm{WS}$ \\
\hline Terço Superior & 30,20 & 30,10 & 31,60 & 31,40 & 30,70 & 31,40 \\
\hline Terço Médio & 31,40 & 30,30 & 32,50 & 29,40 & 27,90 & 30,90 \\
\hline Terço Inferior & 29,10 & 29,60 & 31,20 & 28,30 & 28,70 & 30,70 \\
\hline Média & 30,23 & 30,00 & 31,77 & 29,70 & 29,10 & 31,00 \\
\hline \multirow{2}{*}{ Alongamento da fibra (\%) } & \multicolumn{2}{|c|}{$1^{\mathrm{a}}$ Semana } & \multicolumn{2}{|c|}{$2^{\mathrm{a}}$ Semana } & \multicolumn{2}{|c|}{$3^{\mathrm{a}}$ Semana } \\
\hline & FM 944GL & TMG $81 \mathrm{WS}$ & FM 944GL & TMG $81 \mathrm{WS}$ & FM 944GL & TMG $81 \mathrm{WS}$ \\
\hline Terço Superior & 6,90 & 6,60 & 6,40 & 6,50 & 6,40 & 6,80 \\
\hline Terço Médio & 6,70 & 7,10 & 7,20 & 7,30 & 6,60 & 6,60 \\
\hline Terço Inferior & 7,20 & 6,90 & 6,90 & 6,90 & 6,80 & 7,00 \\
\hline Média & 6,93 & 6,87 & 6,83 & 6,90 & 6,60 & 6,80 \\
\hline
\end{tabular}

Fonte: Autores.

Na Tabela 3 são apresentadas as variações nos valores médios do índice micronaire, maturidade da fibra, índice de fibra curta e índice de fiabilidade em função do atraso na colheita. O atraso na colheita diminuiu os valores médios do índice micronaire ao longo do tempo, todavia não influenciou na maturidade da fibra. Em geral, as cultivares FM 944GL e TMG 81 WS atingiram médias de 4,82 e 4,51 $\mu \mathrm{g}$ in $^{-1}$ para o índice micronaire, respectivamente, enquanto a maturidade apresentou valores percentuais em torno de $87 \%$ para ambas as cultivares. Além disso, nota-se superioridade da cultivar FM 944GL para ambas as características.

Verifica-se que entre as posições na planta, os maiores valores médios do índice micronaire se localizam no terço superior, seguido do terço médio e inferior da cultivar FM 944GL. Não foi verificada variação dos valores médios nas posições da cultivar TMG 81 WS. Assim como, não houve variação expressiva nos valores médios da maturidade da fibra para ambas as cultivares, em relação a posição na planta.

Morello et al. (2015) ao verificar o desempenho de cultivares de algodoeiro em duas localidades no cerrado do estado da Bahia, constatou médias do índice micronaire de 4,9 $\mu \mathrm{g}$ in $^{-1}$ para a FM 944GL e 4,8 $\mu \mathrm{g}$ in ${ }^{-1}$ para a TMG 81 WS, em relação a maturidade da fibra obtiveram média geral de $87 \%$. Em ensaio realizado na mesma região deste estudo, Farias et al. (2015) observaram valores médios do índice micronaire de 4,83 $\mu \mathrm{g} \mathrm{in}^{-1}$ para a cultivar FM 944GL e 4,91 $\mu \mathrm{g}$ in ${ }^{-1}$ para a TMG 81 WS, a maturidade não diferiu entre cultivares, apresentando valor médio de $88 \%$, corroborando com os resultados apresentados. Coutinho et al. (2015) observaram médias do índice micronaire e maturidade de $4,5 \mu \mathrm{g} \mathrm{in}^{-1}$ e $83,7 \%$, respectivamente, para sete cultivares de algodoeiro na região do semiárido mineiro.

O índice de micronaire refere-se a finura de fibra e de acordo com Santana, et al. (2008), os valores ideais de micronaire são de 3,9 a 4,5 $\mu \mathrm{g}$ in $^{-1}$. Além disso, os mesmos autores afirmam que uma fibra madura deve apresentar valor maior que $85,0 \%$ e que valores abaixo de $80,0 \%$ são consideradas como fibra imatura, sendo rejeitadas pela indústria têxtil pois 
podem causar defeitos nos tecidos. Logo, nota-se que mesmo com a tendência de redução ao longo do tempo, o índice de micronaire manteve-se com médias no intervalo desejado, o mesmo resultado também foi observado para a maturidade da fibra, independentemente do tempo e da posição.

$\mathrm{O}$ atraso na colheita não modificou o índice de fibras curtas e de fiabilidade da fibra do algodão, com médias gerais de 5,14 e 5,40\% e de 2.388 e 2.393 para as cultivares FM 944GL e TMG 81 WS, respectivamente.

Em relação as semanas, perceba-se tendência de maiores índices de fibras curtas na $2^{\mathrm{a}}$ semana de colheita, em ambas as cultivares, condizendo com os valores apresentados do comprimento da fibra, exibindo os menores comprimentos médios na $2^{\mathrm{a}}$ semana, possivelmente ocasionados por uma maior incidência de pragas ou doenças, ou ainda deficiência nutricional da área, visto o material ter sido colhido em posição paralela nos talhões das cultivares avaliadas. No índice de fiabilidade, verifica-se as maiores médias na $1^{\mathrm{a}}$ semana de colheita para a cultivar FM 944GL e na $3^{\mathrm{a}}$ semana de colheita da cultivar TMG 81 WS.

Observa-se que o índice de fibras curtas apresentou pouca variação em relação a posição do capulho na planta, mas identifica-se maiores médias no terço superior, em ambas as cultivares. Por outro lado, para o índice de fiabilidade obteve-se valores médios superiores no terço superior, seguido do terço médio e inferior para a cultivar FM 944GL, enquanto, para TMG $81 \mathrm{WS}$, as maiores médias foram visualizadas nos terços inferiores, seguido do terço médio e superior.

Outras pesquisas corroboraram com os dados apresentados, como citado por Farias et al. (2015), as cultivares FM 944GL e TMG 81 WS apresentaram valores percentuais médios do índice de fibras curtas entre 7,86 e 8,14\% e valores médios do índice de fiabilidade entre 2.394 e 2.270, respectivamente. Coutinho et al. (2015), analisando a qualidade de fibra de sete cultivares de algodoeiro, encontraram médias do índice de fibras curtas de 7,41\% e de alta fiabilidade de 2.763 , respectivamente. Lima et al. (2018), estudando a qualidade da fibra sob déficit hídrico, alcançaram médias do índice de fibras curtas de 6,62 e 5,85\% para as cultivares BRS 286 e BRS 336, respectivamente.

A despeito da importância dessas variáveis para a indústria têxtil, Vasconcelos (2016) afirma que o índice de fibras curtas é bastante demandado pela indústria têxtil, porque quanto menor esse índice, maior é o comprimento da fibra, como verificado nas Tabelas 2 e 3. Além disso, tem-se maior interesse em valores médios inferiores a 12,0\%, pois, quanto menor esse índice, melhor é o desempenho das fibras no processo de fabricação do fio (Cordão Sobrinho et al., 2015) e maior qualidade da fibra (Fonseca \& Santana, 2002). Enquanto que o índice de fiabilidade das fibras desejado pela indústria têxtil situa-se entre 2.000 e 2.500 (Santana et al., 2004).

Para o índice de fibras curtas, independente do atraso na colheita, as médias gerais de ambas as cultivares situaram-se na faixa indicada com ideal pela indústria têxtil, provavelmente devido ao descaroçamento de forma manual. Quanto ao índice de fiabilidade, ainda que tenha ocorrido variações ao longo do tempo e entre as cultivares, a mesma não foi o suficiente para que representassem perdas significativas na qualidade da fibra, situando-se dentro dos padrões aceitáveis pela indústria têxtil. 
Tabela 3. Valores médios observados do índice de micronaire, maturidade, índice de fibras curtas e índice de fiabilidade da fibra de duas cultivares de algodão, em diferentes posições na planta e, em função do atraso na colheita.

\begin{tabular}{|c|c|c|c|c|c|c|}
\hline \multirow{2}{*}{ Índice micronaire $\left(\mu \mathrm{g}\right.$ in $\left.^{-1}\right)$} & \multicolumn{2}{|c|}{$1^{\text {a }}$ Semana } & \multicolumn{2}{|c|}{$2^{\mathrm{a}}$ Semana } & \multicolumn{2}{|c|}{$3^{\text {a }}$ Semana } \\
\hline & FM 944GL & TMG $81 \mathrm{WS}$ & FM 944GL & TMG $81 \mathrm{WS}$ & FM 944GL & TMG $81 \mathrm{WS}$ \\
\hline Terço Superior & 5,40 & 4,60 & 4,80 & 4,60 & 4,90 & 4,20 \\
\hline Terço Médio & 5,00 & 4,70 & 4,80 & 4,60 & 4,80 & 4,30 \\
\hline Terço Inferior & 4,60 & 4,60 & 4,40 & 4,40 & 4,70 & 4,60 \\
\hline Média & 5,00 & 4,63 & 4,67 & 4,53 & 4,80 & 4,37 \\
\hline \multirow{2}{*}{ Maturidade da fibra (\%) } & \multicolumn{2}{|c|}{$1^{\mathrm{a}}$ Semana } & \multicolumn{2}{|c|}{$2^{\mathrm{a}}$ Semana } & \multicolumn{2}{|c|}{$3^{\text {a }}$ Semana } \\
\hline & FM 944GL & TMG $81 \mathrm{WS}$ & FM 944GL & TMG $81 \mathrm{WS}$ & FM 944GL & TMG $81 \mathrm{WS}$ \\
\hline Terço Superior & 88,00 & 87,00 & 87,00 & 87,00 & 88,00 & 86,00 \\
\hline Terço Médio & 87,00 & 87,00 & 87,00 & 86,00 & 87,00 & 86,00 \\
\hline Terço Inferior & 86,00 & 87,00 & 86,00 & 86,00 & 87,00 & 87,00 \\
\hline Média & 87,00 & 87,00 & 86,70 & 86,30 & 87,30 & 86,30 \\
\hline \multirow{2}{*}{ Índice de fibras curtas $(\%)$} & \multicolumn{2}{|c|}{$1^{\mathrm{a}}$ Semana } & \multicolumn{2}{|c|}{$2^{\mathrm{a}}$ Semana } & \multicolumn{2}{|c|}{$3^{\mathrm{a}}$ Semana } \\
\hline & FM 944GL & TMG $81 \mathrm{WS}$ & FM 944GL & TMG $81 \mathrm{WS}$ & FM 944GL & TMG $81 \mathrm{WS}$ \\
\hline Terço Superior & 5,50 & 5,40 & 5,30 & 5,80 & 5,00 & 5,60 \\
\hline Terço Médio & 4,60 & 5,40 & 5,30 & 5,50 & 5,00 & 5,50 \\
\hline Terço Inferior & 5,00 & 4,70 & 5,50 & 6,00 & 5,10 & 4,70 \\
\hline Média & 5,03 & 5,17 & 5,37 & 5,77 & 5,03 & 5,27 \\
\hline \multirow{2}{*}{$\begin{array}{l}\text { Índice de fiabilidade } \\
\text { (adimensional) }\end{array}$} & \multicolumn{2}{|c|}{$1^{\mathrm{a}}$ Semana } & \multicolumn{2}{|c|}{$2^{\mathrm{a}}$ Semana } & \multicolumn{2}{|c|}{$3^{\mathrm{a}}$ Semana } \\
\hline & FM 944GL & TMG $81 \mathrm{WS}$ & FM 944GL & TMG $81 \mathrm{WS}$ & FM 944GL & TMG $81 \mathrm{WS}$ \\
\hline Terço Superior & 2.295 & 2.357 & 2.388 & 2.379 & 2.387 & 2.384 \\
\hline Terço Médio & 2.450 & 2.344 & 2.348 & 2.424 & 2.333 & 2.451 \\
\hline Terço Inferior & 2.445 & 2.400 & 2.432 & 2.355 & 2.417 & 2.444 \\
\hline Média & 2.397 & 2.367 & 2.389 & 2.386 & 2.379 & 2.426 \\
\hline
\end{tabular}

Fonte: Autores.

As variações nos valores médios do grau de refletância, índice de amarelecimento e grau de cor em função do atraso na colheita são apresentados na Tabela 4. O atraso na colheita não descaracterizou o grau de refletância e o índice de amarelecimento da fibra do algodão. Observa-se que os valores médios do grau de reflectância para as cultivares FM 944GL e TMG 81 WS foram de 81,1 e $80,5 \%$, respectivamente, ao passo que no índice de amarelecimento, obteve-se média de 7,3 em ambas as cultivares.

Segundo Freire (2015), o aumento da exposição da pluma do algodão no campo, implica em um escurecimento progressivo da cor das fibras, isto é, o percentual da reflectância diminui, tendo como resultado, uma fibra mais cinza, com redução do brilho e proliferação de microrganismos, que destruirão a celulose das fibras. Todavia, percebe-se que o tempo de permanência em campo dos capulhos abertos, não refletiu em tendência de redução da reflectância, provavelmente pelo fato da cultura ser colhida em época de seca na região em que foi realizado o estudo.

Em relação a posição na planta, nota-se tendência de maiores médias tanto para o grau de reflectância quanto para o índice de amarelecimento no terço superior, podendo ser decorrente das condições do ambiente, onde nesta posição, o algodão permanece mais exposto a luz solar, desenvolvendo-se melhor que nas posições abaixo e apresentando menor teor de água, o que pode exercer influência sobre a qualidade na fibra. Observa-se que a cultivar FM 944GL na $1^{\mathrm{a}}$ semana apresentou valores superiores no grau de reflectância, contudo, nota-se variação importante na posição intermediária da $2^{\mathrm{a}}$ a $3^{\mathrm{a}}$ semana, ao passo que na cultivar TMG $81 \mathrm{WS}$, visualiza-se aumento da $1^{\mathrm{a}}$ a $3^{\mathrm{a}}$ semana para esta variável. Além disso, constata-se que da primeira para a última semana de coleta houve pouca variação do índice de amarelecimento, sendo maior no terço superior e menor no terço médio.

Vilela e Bélot (2015) verificaram médias de grau de reflectância de 81,6 e 78,5\% e médias de 8,5 e 8,8 para o índice de amarelecimento das cultivares FM 944GL e TMG 81 WS, na devida ordem. Nota-se que os valores médios do índice de 
amarelecimento obtidos para ambas as cultivares estudadas foram inferiores aos observados por Vilela e Bélot (2015). Os resultados citados no trabalho de Coutinho et al. (2015) foram semelhantes aos deste estudo, com valores médios de 79,5\% e 7,48, respectivamente, para o grau de reflectância e índice de amarelecimento.

As indústrias têxteis, de modo geral, buscam por plumas com maiores percentuais de reflectância e menores índices de amarelecimento. Assim, pode-se afirmar que mesmo com atraso de mais de duas semanas para realização da colheita, as cultivares analisadas neste estudo, mostraram valores adequados para essas características, estando de acordo com o observado em literatura.

Em relação a cor da fibra, nota-se que o atraso na colheita, para o intervalo de tempo analisado, não afetou o grau de cor do algodão, sendo colhido algodão com cor dentro do considerado adequado para o mercado, porém, perceba-se uma inclinação de redução da cor ao longo do tempo.

O grau de cor é determinado por meio da combinação entre os valores do grau de reflectância e do grau de amarelecimento interpolados no diagrama de cores de Nickerson \& Hunter fornecido pelo Departamento de Agricultura dos Estados Unidos - USDA. O grau de cor é representado por um código numérico com três dígitos, sendo o primeiro relativo ao tipo visual do algodão (tipo 1 é o melhor e o 8 já é considerado fora do padrão), o segundo refere-se à cor (1-branco, 2ligeiramente creme, 3-creme, 4-avermelhado e 5-amarelado), e o terceiro representa um dos quadrantes localizados no diagrama de cores (Costa et al., 2006; Brasil, 2002).

De modo geral verifica-se que as cultivares, no terço superior, mantiveram o grau de cor do tipo 21 , que caracteriza algodão branco de cor estritamente média. No terço médio, nota-se uma queda no índice de cor para algodão tipo 31, entretanto, essa queda não afeta de maneira expressiva a cor do produto, classificando-o ainda na cor branca, porém de tom médio. No terço inferior, a cultivar FM 944GL obteve melhores resultados do grau de cor da $1^{\mathrm{a}}$ a $3^{\mathrm{a}}$ semana quando contrastado com a cultivar TMG 81 WS.

Segundo Coutinho et al. (2015) e Fiedler (2007), o Brasil produz em grande parte, algodão do tipo 41-4 (cor branca, estritamente abaixo da média), pois é o padrão que o mercado nacional consome, enquanto o mercado internacional opta por um algodão tipo 31-3 (cor branca, média) e o 21-2 (cor branca, estritamente média). Assim, as fibras de algodão produzidas pelas cultivares FM 944GL e TMG 81 WS e nas condições climáticas de Ipiranga do Norte do estado de Mato Grosso, apresentam qualidade e potencial para exportação. 
Tabela 4. Valores médios observados do grau de refletância, índice de amarelecimento e grau de cor de duas cultivares de algodão, em diferentes posições na planta e, em função do atraso na colheita.

\begin{tabular}{lcccccc}
\hline \multirow{2}{*}{ Grau de reflectância (\%) } & \multicolumn{2}{c}{$1^{\text {a }}$ Semana } & \multicolumn{2}{c}{$2^{\text {a }}$ Semana } & \multicolumn{2}{c}{$3^{\text {a }}$ Semana } \\
\cline { 2 - 7 } & FM 944GL & TMG 81 WS & FM 94 GL & TMG 81 WS & FM 944GL & TMG 81 WS \\
\hline Terço Superior & 81,40 & 80,90 & 81,70 & 81,00 & 81,30 & 82,10 \\
Terço Médio & 81,40 & 79,40 & 80,40 & 81,40 & 78,70 & 81,20 \\
Terço Inferior & 81,70 & 79,00 & 81,50 & 79,50 & 81,90 & 80,00 \\
\hline Média & 81,50 & 79,80 & 81,20 & 80,60 & 80,60 & 81,10 \\
\hline Índice de amarelecimento (+b) & \multicolumn{2}{c}{$1^{\text {a }}$ Semana } & \multicolumn{2}{c}{$2^{\text {a Semana }}$} & $3^{\text {a Semana }}$ \\
\cline { 2 - 8 } & FM 944GL & TMG 81 WS & FM 944GL & TMG 81 WS & FM 944GL & TMG 81 WS \\
\hline Terço Superior & 8,20 & 8,10 & 7,40 & 8,10 & 7,60 & 7,90 \\
Terço Médio & 6,80 & 7,40 & 6,70 & 6,60 & 6,90 & 7,10 \\
Terço Inferior & 7,70 & 7,00 & 7,30 & 7,20 & 7,00 & 6,70 \\
\hline Média & 7,60 & 7,50 & 7,10 & 7,30 & 7,20 & 7,20 \\
\hline \multirow{2}{*}{ Grau de cor } & \multicolumn{2}{c}{$1^{\text {a Semana }}$} & \multicolumn{2}{c}{$2^{\text {a Semana }}$} & $3^{\text {a Semana }}$ \\
\hline Terço Superior & FM 944GL & TMG 81 WS & FM 944GL & TMG 81 WS & FM 944GL & TMG 81 WS \\
Terço Médio & $21-1$ & $21-1$ & $21-1$ & $21-1$ & $21-2$ & $21-1$ \\
Terço Inferior & $31-1$ & $31-2$ & $31-2$ & $31-1$ & $31-2$ & $31-1$ \\
\hline
\end{tabular}

Fonte: Autores.

As variações nos valores médios do número de partículas de impurezas superficiais (count), percentual da área ocupada pelas partículas de impurezas na superfície e grau de folha em função do atraso na colheita são apresentados na Tabela 5. Analisando as impurezas na fibra durante o atraso na colheita, percebe-se pouca variação entre o número de partículas, área com impurezas e grau de folha, entretanto, há tendência de maiores valores para a cultivar TMG 81 WS. As cultivares apresentaram médias gerais de 0,60 e 0,43\% de área e de 73,55 e 68,11 partículas de impureza, refletindo em um grau de folha de 4 e 3, respectivamente, para as cultivares TMG 81 WS e FM 944GL.

A cultivar FM 944GL apresentou pouca variação do aspecto de impurezas durante as duas primeiras semanas de colheita, porém, houve acréscimos do grau de folha na última semana. Provavelmente em decorrência das folhas estarem mais secas e permanecerem aderidas as fibras. Destaca-se também a ação do vento a medida em que ocorre a desfolha, em que as impurezas são movimentadas no talhão e acabam contaminando as fibras. A cultivar TMG 81 WS exibiu oscilações ao longo do tempo, manifestando queda nas contaminações da $1^{\mathrm{a}}$ a $2^{\mathrm{a}}$ semana de colheita, e acréscimo da $2^{\mathrm{a}}$ a $3^{\mathrm{a}}$ semana.

Entre as posições na planta da cultivar FM 944GL, destaca-se o terço médio com as maiores médias para área e número de partículas, enquanto na cultivar TMG 81 WS, a posição de destaque ficou com o terço inferior. Nota-se na $2^{\mathrm{a}}$ semana de colheita e no terço inferior da cultivar TMG $81 \mathrm{WS}$, baixos valores do número de partículas, entretanto uma grande área ocupada pela mesma, identificando-se que, apesar do pequeno número de partículas, o tamanho das mesmas era superior quando comparadas com outras posições. Verifica-se ao longo de todas as posições na $3^{\text {a }}$ semana de colheita, médias superiores do número de partículas em relação a área, ou seja, porções menores de partículas, porém em maiores quantidades. 
Tabela 5. Valores médios observados do número de partículas de impurezas superficiais (count), percentual da área ocupada pelas partículas de impurezas presente na superfície e grau de folha de duas cultivares de algodão, em diferentes posições na planta e, em função do atraso na colheita.

\begin{tabular}{|c|c|c|c|c|c|c|}
\hline \multirow{2}{*}{ Número de partículas (count) } & \multicolumn{2}{|c|}{$1^{\mathrm{a}}$ Semana } & \multicolumn{2}{|c|}{$2^{\mathrm{a}}$ Semana } & \multicolumn{2}{|c|}{$3^{\mathrm{a}}$ Semana } \\
\hline & FM 944 GL & TMG $81 \mathrm{WS}$ & FM 944 GL & TMG $81 \mathrm{WS}$ & FM 944 GL & TMG $81 \mathrm{WS}$ \\
\hline Terço Superior & 62,00 & 71,00 & 68,00 & 65,00 & 71,00 & 73,00 \\
\hline Terço Médio & 69,00 & 82,00 & 66,00 & 66,00 & 72,00 & 76,00 \\
\hline Terço Inferior & 66,00 & 76,00 & 62,00 & 65,00 & 77,00 & 88,00 \\
\hline Média & 65,67 & 76,33 & 65,33 & 65,33 & 73,33 & 79,00 \\
\hline \multirow{2}{*}{ Área com impurezas (\%) } & \multicolumn{2}{|c|}{$1^{\mathrm{a}}$ Semana } & \multicolumn{2}{|c|}{$2^{\mathrm{a}}$ Semana } & \multicolumn{2}{|c|}{$3^{\mathrm{a}}$ Semana } \\
\hline & FM 944 GL & TMG $81 \mathrm{WS}$ & FM 944 GL & TMG $81 \mathrm{WS}$ & FM 944 GL & TMG $81 \mathrm{WS}$ \\
\hline Terço Superior & 0,30 & 0,50 & 0,30 & 0,50 & 0,50 & 0,40 \\
\hline Terço Médio & 0,40 & 0,80 & 0,40 & 0,40 & 0,80 & 0,50 \\
\hline Terço Inferior & 0,40 & 0,90 & 0,30 & 1,00 & 0,60 & 0,70 \\
\hline Média & 0,40 & 0,70 & 0,30 & 0,60 & 0,60 & 0,50 \\
\hline \multirow{2}{*}{ Grau da folha (adimensional) } & \multicolumn{2}{|c|}{$1^{\mathrm{a}}$ Semana } & \multicolumn{2}{|c|}{$2^{\mathrm{a}}$ Semana } & \multicolumn{2}{|c|}{$3^{\mathrm{a}}$ Semana } \\
\hline & FM 944 GL & TMG $81 \mathrm{WS}$ & FM 944 GL & TMG $81 \mathrm{WS}$ & FM 944 GL & TMG $81 \mathrm{WS}$ \\
\hline Terço Superior & 3,00 & 4,00 & 3,00 & 4,00 & 4,00 & 3,00 \\
\hline Terço Médio & 3,25 & 4,75 & 3,50 & 3,75 & 5,25 & 4,25 \\
\hline Terço Inferior & 3,00 & 5,75 & 3,00 & 6,00 & 4,00 & 5,00 \\
\hline
\end{tabular}

Fonte: Autores.

\subsection{Rendimento da fibra e características físicas dos capulhos}

O atraso na colheita não reduziu o rendimento da fibra do algodão, com médias gerais de 46,20 e 44,36\%, respectivamente, para as cultivares FM 944GL e TMG 81 WS (Figura 5). Segundo a Basf (2019), o rendimento da fibra para a cultivar FM 944GL em torno de 40,0\%, ao passo que para a cultivar TMG 81 WS é esperado rendimento de fibra em torno de 43,3\% (TMG, 2016). Logo, o rendimento de fibra observado foi superior quando contraposto ao indicado pelas fabricantes das cultivares. Dois fatores podem ter influenciado no resultado, colheita realizada manualmente com retirada de todo o material da planta, e menor contaminação, quebra e sujeira da fibra quando comparada com a colheita mecânica, e o descaroçamento manual, possibilitando a separação total da fibra e caroço.

Verifica-se que as médias do rendimento da fibra se mantiveram estáveis durante as semanas de colheita para as duas cultivares. Além disso, nota-se uma tendência de que os maiores valores de rendimento de fibra foram para a cultivar FM 944GL, como também há a tendência de nos terços superiores, para ambas as cultivares ser maior, reduzindo nos terços médios e obtendo os menores rendimentos no terço inferior.

A variação entre o menor e o maior rendimento da fibra foi de $6,3 \%$, sendo o menor obtido no terço inferior da $2^{\mathrm{a}}$ semana de coleta da cultivar 81 WS e, o maior, na ponteira da planta na $1^{\text {a }}$ semana de coleta, para a cultivar FM 944GL. Salvo a variação entre as posições, verifica-se médias de 46,2 e 44,4 \% para as cultivares FM 944GL e 81 WS, respectivamente, apresentando diferença de $1,8 \%$.

Em ensaio realizado com cultivares de algodoeiro herbáceo na região de Sinop, MT, Farias et al. (2015) verificaram resultados médios de porcentagem de fibra de 45,3 e 46,6\% para as cultivares FM 944GL e TMG 81 WS, respectivamente, sendo próximo ao observado neste estudo. Valores menores foram observados por Vilela e Bélot (2015) em estudo realizado no município de Sorriso, MT, sendo em torno de 40,7\%. E ainda, Bélot et al. (2017) avaliando a safra 2015/16 no município de Sorriso, MT, obtiveram rendimento de fibra em torno de 40,84\%.

O rendimento da fibra é a relação entre o peso da fibra sem caroço pelo peso da fibra com caroço. Assim, a importância do rendimento de fibra está no preço pago pela arroba da pluma, em média, 3,5 vezes superior àquele pago pela 
arroba do algodão em caroço. Portanto, o rendimento de fibra, para o produtor de algodão, é a característica de maior interesse, constituindo, aproximadamente, $90 \%$ do valor da produção (Bélot \& Marquié, 2006).

Relacionando com os valores médios de rendimento de fibra obtidos neste estudo realizado no município de Ipiranga do Norte, MT, com os dados citados, constata-se médias superiores de rendimento de fibra tanto para a cultivar FM 944GL quanto para a cultivar TMG 81 WS, para a maioria das fontes de variação, ou seja, cultivar, posição do capulho na planta e época de colheita.

Figura 5. Valores médios observados do rendimento de fibra de duas cultivares, em diferentes posições na planta e, em função do atraso na colheita. Em que: (Sup.) terço superior; (Med.) terço médio; (Inf.) terço inferior.

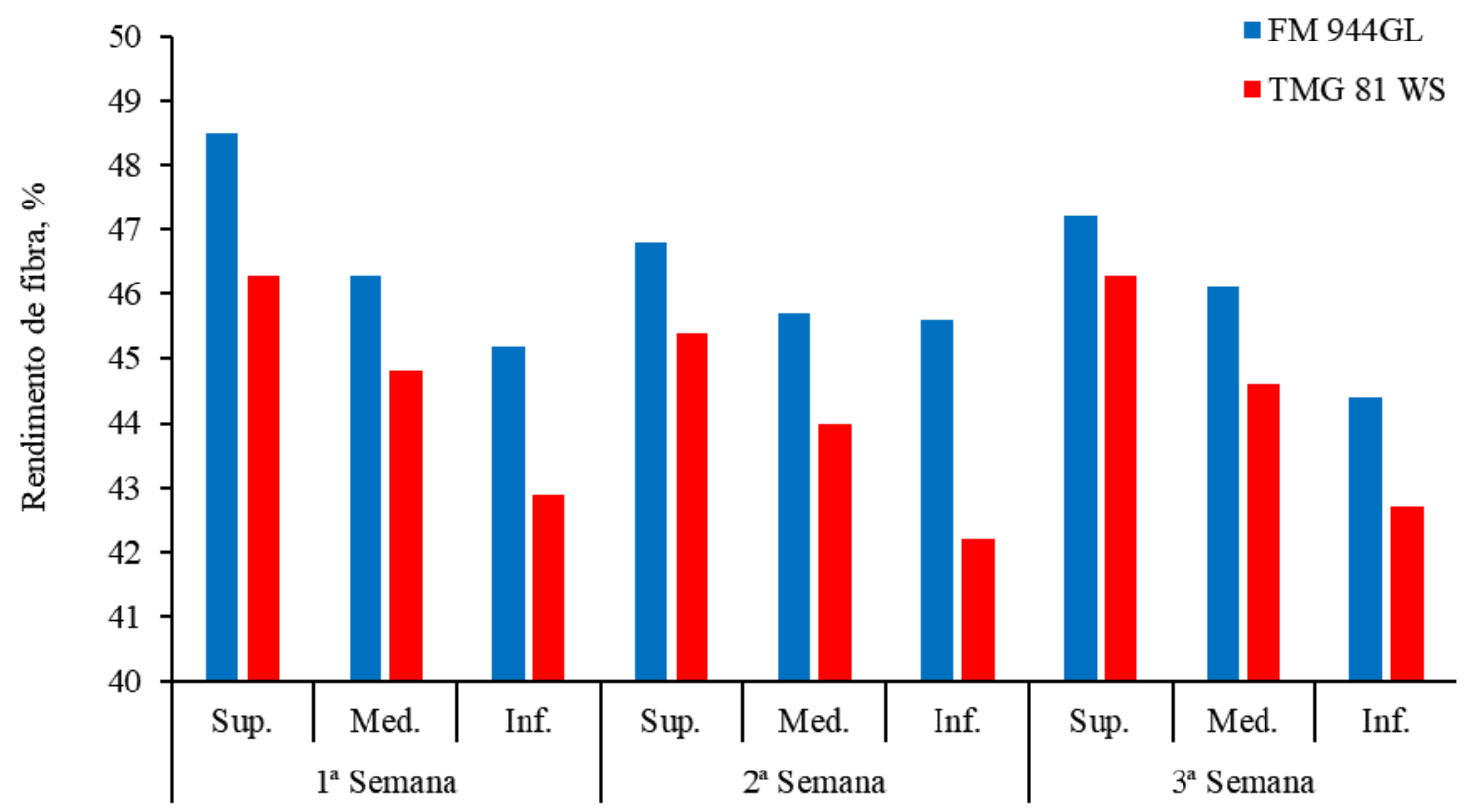

Fonte: Autores.

O atraso na colheita não influenciou na massa total, assim como, do caroço e da fibra para as cultivares FM 944GL e TMG 81 WS, com valores médios, respectivamente, de 5,07 e 5,48 g na massa total de 2,72 e 3,07 g no caroço e de 2,34 e 2,43 g na fibra (Figura 6). Desta forma, aproximadamente $53,65 \%$ da massa total do capulho é caroço e $46,15 \%$ é pluma na cultivar FM 944GL. Na cultivar TMG 81 WS, cerca de 56,02\% da massa total é caroço e 44,34\% é pluma. Determinando assim, superioridade da cultivar TMG 81 WS para a massa média. De acordo com a Basf (2019), o peso dos capulhos da cultivar FM 944GL situa-se entre 4,5 e 5,5 g, e a TMG (2016) aponta que o peso dos capulhos (total) da cultivar TMG 81 WS é de 4,89 g, corroborando com os dados apresentados.

Em relação as semanas de colheita, houve tendência de aumento de massas (total, caroço e fibra) entre a $1^{\mathrm{a}}$ e a $2^{\mathrm{a}}$ semanas, seguido de leve tendência de redução na $3^{\mathrm{a}}$ semana de colheita. Fora isso, observa-se similaridades entre os valores de massa dos capulhos nas diferentes partes da planta, e ainda, os valores médios de massa dos capulhos foram superiores para a cultivar TMG $81 \mathrm{WS}$, entretanto, a diferença média da massa de fibra entre as cultivares é de apenas $0,1 \mathrm{~g}$. Devido a densidade, nota-se maior massa do caroço em relação a fibra. Por fim, as maiores médias de massa total, caroço e fibra foram registradas no terço superior, e as menores, no terço inferior, para ambas as cultivares.

Farias et al. (2015) avaliando as mesmas cultivares deste estudo, observaram valores de massa do capulho de 4,65 e 4,43 g para as cultivares FM 944GL e TMG 81 WS, respectivamente. Vilela e Bélot (2015) quantificaram massa média dos 
capulhos de 5,63 e 5,48 g para as cultivares FM 944GL e TMG 81 WS, nesta ordem. Cordeiro et al. (2016) também avaliaram a cultivar TMG 81 WS na região Oeste Paulista, e obtiveram massa média de capulho de aproximadamente 4,0 g.

Diante destes resultados, constata-se que os valores de massa de capulhos obtidos neste estudo foram similares ou superiores a outros realizados com os mesmos materiais.

Figura 6. Valores médios observados de massa total, do caroço e da fibra de duas cultivares, em diferentes posições na planta e, em função do atraso na colheita. Em que: (a) terço superior; (b) terço médio; (c) terço inferior; (Tot.) total; (Car.) caroço; (Fib.) fibra.

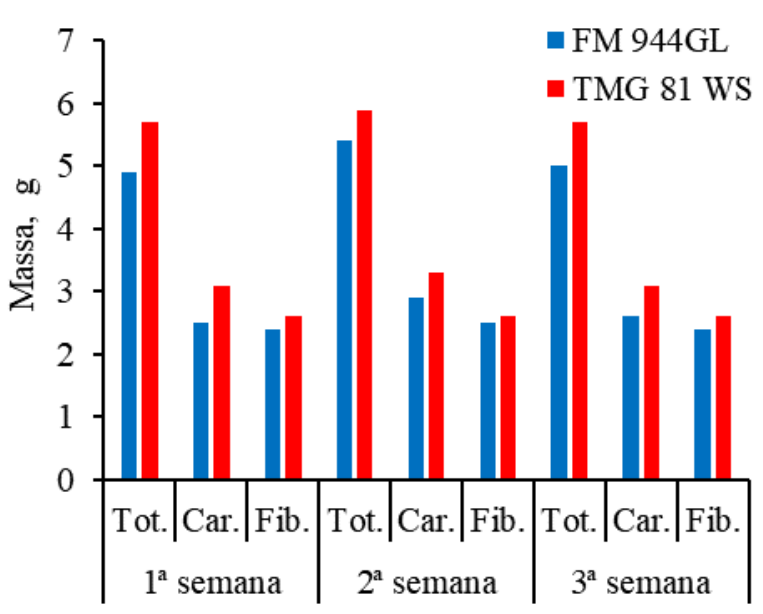

(a)

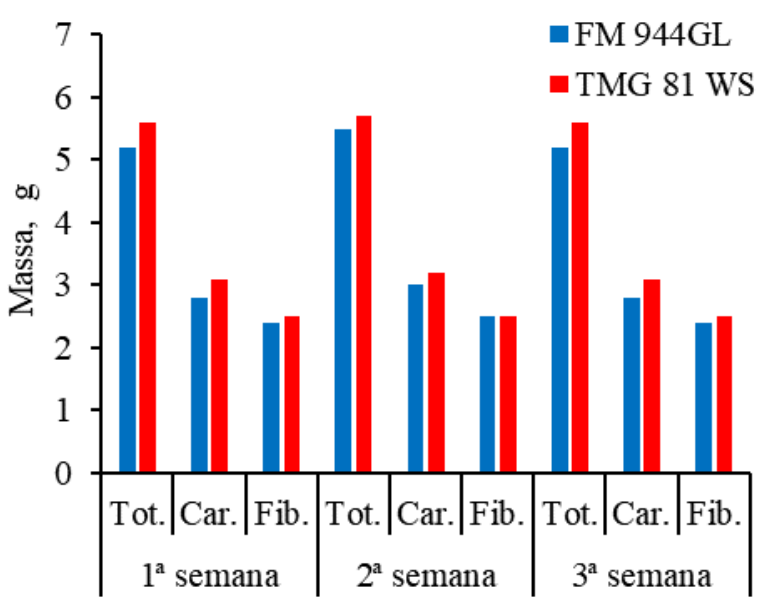

(b)

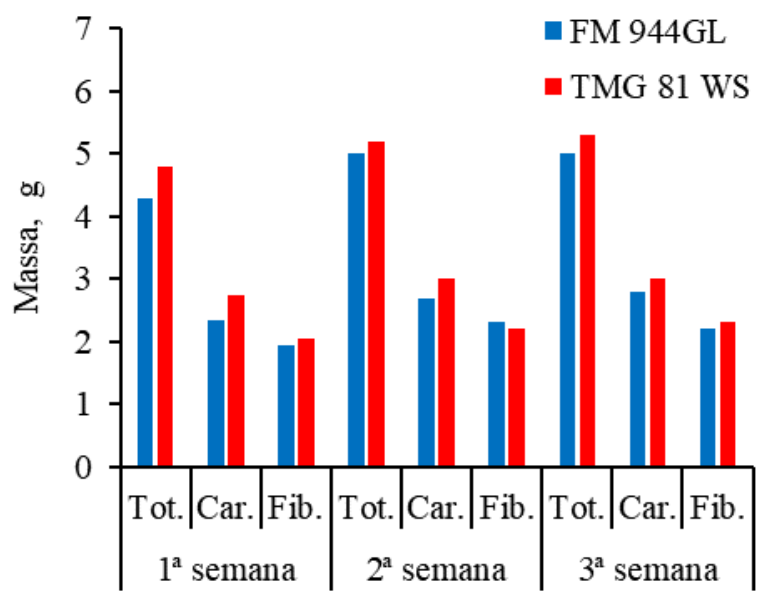

(c)

Fonte: Autores.

\subsection{Atribuição de notas para ágio e deságio na comercialização}

O momento da comercialização é um dos mais importantes dentro da produção do algodoeiro, sendo esse o instante que ocorre o retorno financeiro dos investimentos para a produção da cultura. Os ágios e deságios fazem parte da comercialização do algodão, proporcionando lucros ou prejuízos ao produtor. Dessa forma, buscou-se atribuir notas as devidas características levadas em consideração no momento da comercialização, verificando se ocorreu ágios ou deságios ao decorrer do tempo e nas diferentes posições no capulho na planta.

Nas Figuras 7 e 8 são descritas as notas atribuídas para o ágio e deságio das características da fibra do algodão utilizadas na comercialização, respectivamente, para as cultivares FM 944GL e TMG 81 WS. 
A cultivar FM 944GL, para a resistência, apresentou variações ao longo das semanas e na posição na planta, entretanto, todas as posições alcançaram ágio na $2^{\mathrm{a}}$ semana e o terço superior obteve ágio ao longo das três semanas de colheita, as demais permaneceram como padrão. O índice de micronaire, assim como a resistência, apresentou oscilações ao longo do tempo, todavia, verifica-se ágio apenas no terço superior e médio na $1^{\text {a }}$ semana de colheita, e no terço superior da $3^{\mathrm{a}}$ semana. Apesar de apresentar ótimos valores ao longo do tempo, o restante das amostras manteve-se no valor padrão de comercialização.

A cor alcançou ágio para a maioria das amostras ao longo do tempo e posição na planta, com exceção apenas no terço médio e inferior da $3^{a}$ semana de colheita, que apresentaram valores padrões. $\mathrm{O}$ índice de fibras curtas (SFI), apresentou valores superiores a linha B ao longo do tempo e posição, dessa forma, não ocorreram descontos. Nota-se que índice de fibras curtas foi baixo, condizendo com os valores de comprimento da fibra, que foram altos. Por fim, para o comprimento obteve-se valores superiores a linha A, ou seja, superior a nota 10, caracterizando assim que, independentemente da posição ou tempo de colheita, em relação ao comprimento da fibra haveria ágio.

A cultivar TMG 81 WS apresentou oscilações ao longo das semanas para a resistência, porém, visualiza-se ágio na $3^{a}$ semana em todas as posições da planta, ou seja, caso o produtor queira colher algodão com maior resistência, na $3^{\mathrm{a}}$ semana, de acordo com o que foi avaliado, seria mais indicado, no entanto, não se torna viável devido as perdas de outros fatores ao longo do tempo. Apesar dos bons valores verificados para o índice micronaire, os mesmos não foram suficientes para que houvesse ágio em relação a essa característica, não resultando assim em bônus ao produtor. A cor apenas alcançou ágio no terço superior da $2^{\mathrm{a}}$ e $3^{\mathrm{a}}$ semana, não sendo possível alcançar índices superiores nas outras semanas devido ao grau de folha constituído na fibra ser alto.

Com relação ao índice de fibras curtas (SFI), índice esse caracterizado apenas por deságio, obteve notas superiores a 5, mantendo-se acima da linha B, não acarretando em descontos ao produtor ao longo de todo o tempo de atraso na colheita. Perceba-se valores superiores a linha superior A para o comprimento da fibra, ou seja, verifica-se notas maiores que 10 para o comprimento ao longo do tempo e nas diferentes posições, caracterizando assim, que haveria ágio na comercialização. 
Figura 7. Valores das notas atribuídas para ágio e deságio da resistência, índice micronaire, cor, índice de fibras curtas (SFI) e comprimento da cultivar FM 944GL, em diferentes posições na planta e, em função do atraso na colheita. Em que: (Sup.) terço superior; (Med.) terço médio; (Inf.) terço inferior; (A) limite inferior para ágio; (B) limite superior para deságio.

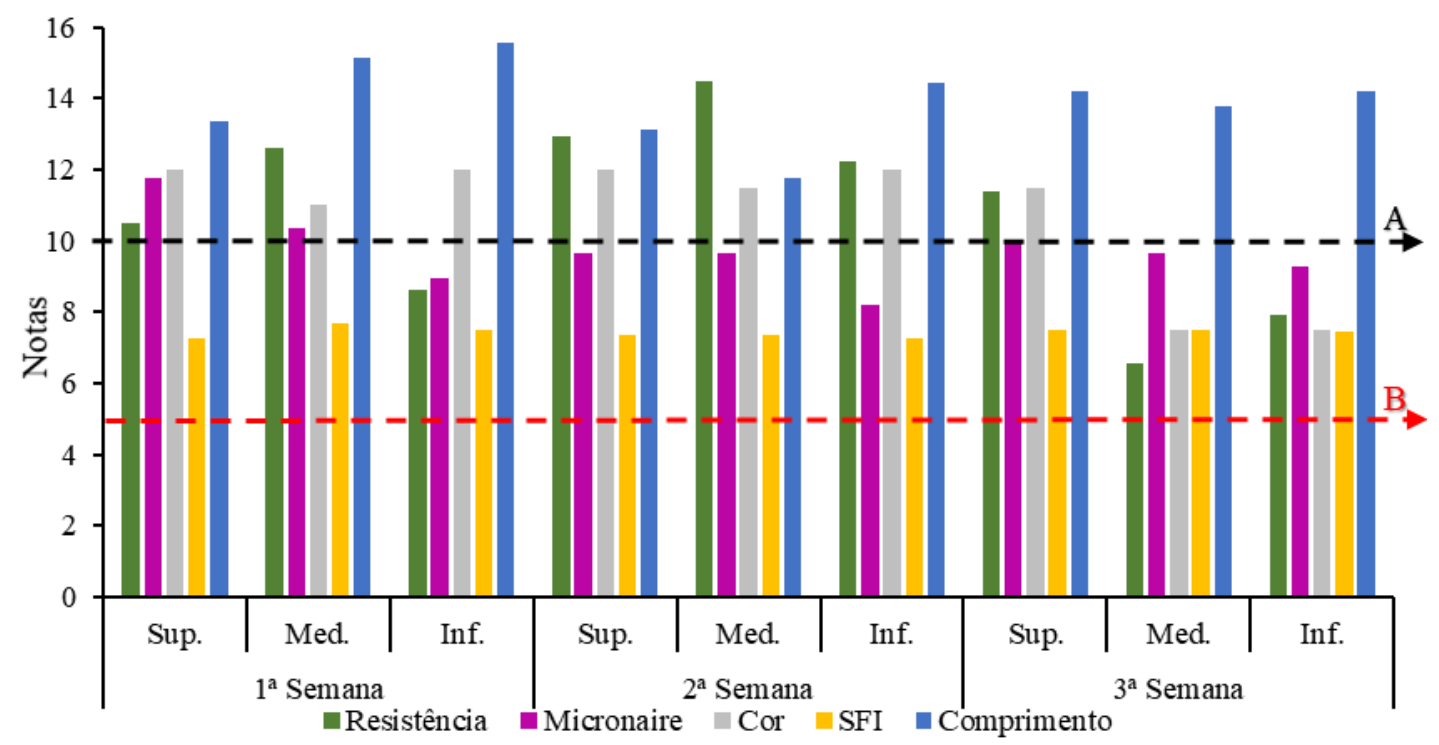

Fonte: Autores.

Figura 8. Valores das notas atribuídas para ágio e deságio da resistência, índice micronaire, cor, índice de fibras curtas (SFI) e comprimento da cultivar TMG 81 WS, em diferentes posições na planta e, em função do atraso na colheita. Em que: (Sup.) terço superior; (Med.) terço médio; (Inf.) terço inferior; (A) limite inferior para ágio; (B) limite superior para deságio.

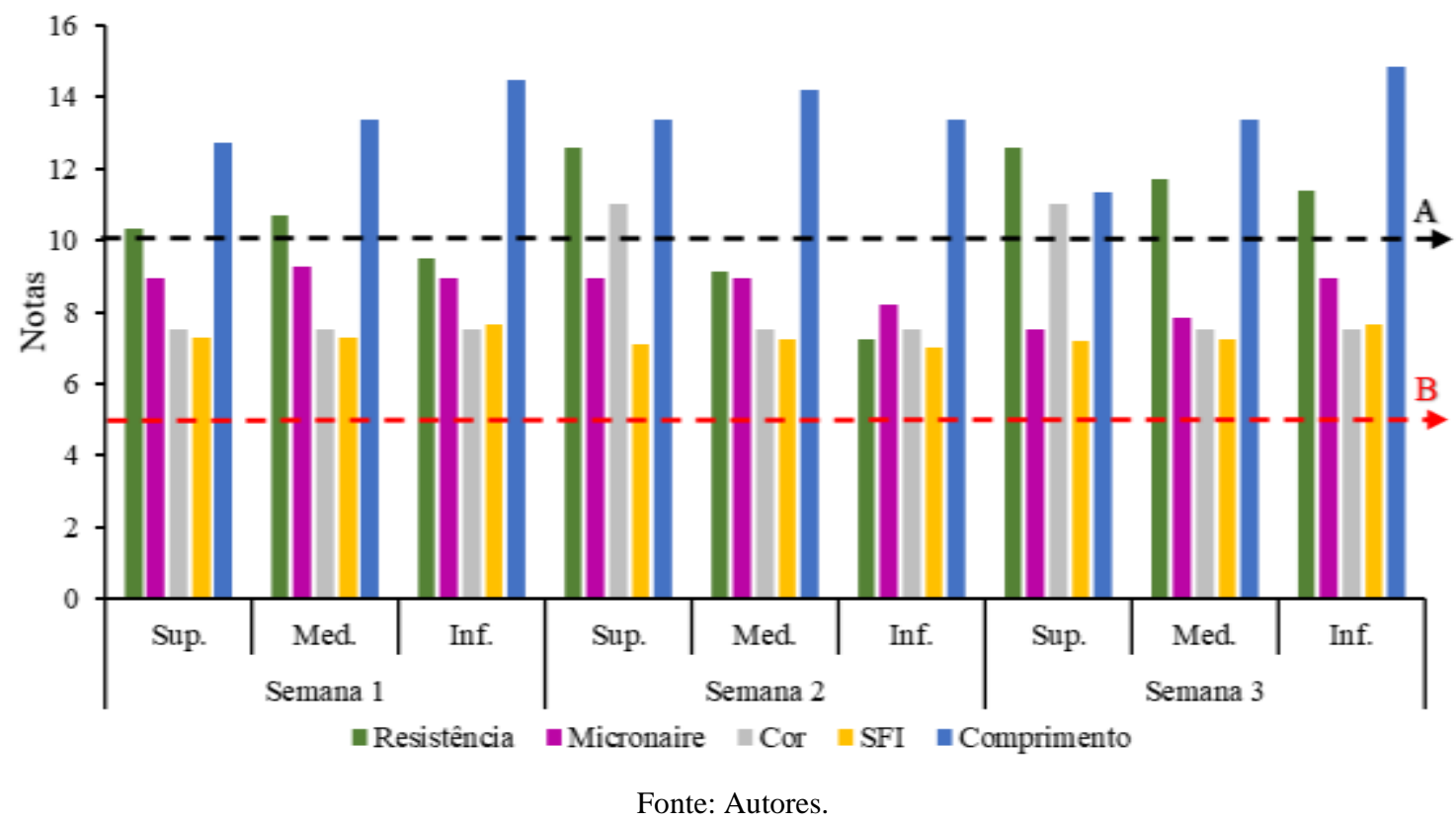

\section{Considerações Finais}

$\mathrm{O}$ atraso na colheita aumenta as perdas quantitativas no solo durante a pré-colheita do algodão em caroço, em virtude do tempo de exposição no campo, das condições climáticas locais e da maturação fisiológica do algodoeiro, e consequentemente maiores prejuízos ao produtor. Devido as diferenças das características dos materiais genéticos, têm-se 


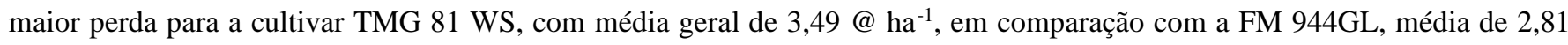
@ ha-1.

Os resultados em relação a perda qualitativa da fibra apontam que o atraso na colheita não descaracteriza o comprimento, uniformidade, resistência, maturidade, índice de fibras curtas, índice de fiabilidade, grau de refletância e índice de amarelecimento, todavia, reduz o alongamento, índice micronaire e grau de cor, além do aumento de partículas de impurezas superficiais na fibra, independente da cultivar.

O atraso na colheita não causa perda no rendimento da fibra do algodão e na massa total do capulho, independente do material genético.

Considerando as condições do experimento, a cultivar FM 944GL demonstra melhor desempenho no que diz respeito ao comprimento, índice micronaire, maturidade da fibra, índice de fibras curtas, grau de reflectância, cor e rendimento da fibra. Enquanto que a cultivar TMG 81 WS apresenta maiores perdas quantitativas na pré-colheita e com maior número de partículas de impurezas superficiais presentes na fibra.

Em relação a posição do capulho na planta, verifica-se fibra de algodão de maior qualidade no terço superior na planta.

O atraso na colheita não resulta em descontos por conta de deságios. O comprimento, a resistência e a cor da fibra apresentam ágios para a maioria das variáveis avaliadas.

Por fim, recomenda-se desse mesmo tipo de avaliação para outras cultivares de algodão em destaque no estado de Mato Grosso, para verificar quais cultivares são mais susceptíveis à perda quantitativa em função do atraso da colheita.

\section{Referências}

ADVFN (2019). Algodão. https://br.advfn.com/commodities/algodao.html

ANEA, Associação nacional dos exportadores de algodão. (2018). Tabela de Ágio e Deságio. http://www.aneacotton.com.br/pt-br/servicos/agio-e-desagio.

Bachelier, B., \& Gourlot, J. P. (2018). A fibra de algodão: origem, estrutura, composição e caracterização. In Bélot, J. L., Manual de qualidade da fibra da Ampa. (p. 28-57). IMAmt, AMPA.

BASF. FM 944GL, 2019. https://agriculture.basf.com/br/pt/protecao-de-cultivos-e-sementes/produtos/fibermax/variedades-fibermax/FM-944GL.html

Bélot, J. L., Vilela, P. M. C. A., Galbieri, R., \& Dutra, S. (2017). Variedades comerciais e pré-comerciais de algodão para o Mato Grosso: síntese de resultados agronômicos e de qualidade de fibra obtidos pelo IMAmt até a safra 2015/16. Circular Técnica 28, 1-24. http://sites.unoeste.br/gea/wpcontent/uploads/2018/09/28-Qualidade-da-fibra-e-produtividade-cultivares-15-16.pdf

Bélot, J. L., \& Marquié, C. (2006). Novos usos podem aumentar importância do caroço. Revista Visão Agrícola, 6, $112-114$.

Brasil. (2009). Regras para análise de sementes. Brasília, Brasil: Ministério da Agricultura. Departamento Nacional de Produção Vegetal.

Brasil. (2002). Instrução Normativa $\mathrm{n}^{\circ}$ 63, de 5 de dezembro de 2002. Aprova o Regulamento técnico de Identidade e de Qualidade para a Classificação do Algodão em Pluma. DOU, 6/12/2012, Seção 1, 6-8.

Carvalho, L. P., Farias, F. J. C., Morello, C. L., Rodrigues, J. I. S., \& Teodoro, P. E. (2015). Agronomic and technical fibers traits in elite genotypes of cotton herbaceous. African Journal of Agricultural Research, 10, 4882-4887. 10.5897/AJAR2015.10515

Carvalho, J. T. (2013). Colheita: operação eficaz para qualidade de fibra. Amipa. Informativo Técnico 22.

CONAB (2021). Tabela de dados-Produção e balanço de oferta e demanda de grãos. https://www.conab.gov.br/info-agro/safras/graos

Costa, J. N., Santana, J. C. F., Rivero, M. J., Andrade, W. J. E. O. \& Sobrinho, R. E. (2006). Padrões Universais para Classificação do Algodão. EMBRAPA ALGODÃO. 22p. (Documentos, 151).

Cordão Sobrinho, F. P., Guerra, H. O., Araújo, W. P., Pereira, J. R., Zonta, J. H., \& Bezerra, J. R. (2015). Fiber quality of upland cotton under different irrigation depths. Revista Brasileira de Engenharia Agrícola e Ambiental, 19(11), 1057-1063. https://doi.org/10.1590/1807-1929/agriambi.v19n11p1057-1063

Cordeiro, C. F. dos S., Peres, V. J. S., \& Echer, F. R. (2016). Produtividade de cultivares de algodão no Oeste Paulista. Colloquium Agrariae, 12 , 68-74. 10.5747/ca.2016.v12.nesp.000173

Coutinho, C. R., Andrade, J. A. S., \& Pegoraro, R. F. (2015). Produtividade e qualidade de fibra de cultivares de algodoeiro (Gossypium hirsutum L.) na região do semiárido mineiro. Essentia, 16(2), 62-82. 
Echer, F., Rosolem, C. A., \& Raphael, J. P. A. (2018). Desenvolvimento da planta e qualidade da fibra. In: Bélot, J. L., Manual de qualidade da fibra da Ampa. (p. 206-237). IMAmt, AMPA.

Farias, F. J. C., Silva Filho, J. L., Morello, C. de L., Suassuna, N. D., Pedrosa, M. B., Lamas, F. M., \& Ribeiro, J. L. (2015). Resultados do ensaio nacional de cultivares do algodoeiro herbáceo nas condições do Cerrado - safra 2013/2014. Embrapa Algodão. Documentos, 257.

Ferronato, A., Pereira, L. C., Júnior, L. D. S., Bezerra, E. L., Bassan, R. C., \& Borges, D. C. (2002). Avaliação e análise de perdas na colheita da cultura do algodão na região sudeste do Estado de Mato Grosso. Congresso Brasileiro de Algodão, 1-5. http://www.cnpa.embrapa.br/produtos/algodao/p ublicacoes/trabalhos_cba4/202.pdf

Fiedler, H. A. (2007). Tecnologia e qualidade do algodão para exportação. In Farias, F. J. C. et al. Tecnologia para o algodoeiro no cerrado do Mato Grosso. (p.111-118). Embrapa Algodão.

Fonseca, R. G. \& Santana, J. C. F. (2002). Resultados de ensaio HVI e suas interpretações (ASTM D-4605). Embrapa Algodão. Circular Técnica, 66.

Freire, E. C. (2015). Algodão no cerrado do Brasil. Gráfica e Editora Positiva.

INMET (2020). Histórico de dados meteorológicos. https://portal.inmet.gov.br/dadoshistoricos.

Köppen, W., \& Geiger, R. (1936). Classificação climática de Köppen-Geiger. https://portais.ufg.br/up/68/o/Classifica o_Clim_tica_Koppen.pdf

Lama, S. F. M., \& Chitarra, L. G. (2014). Diagnóstico dos sistemas de produção de algodão em Mato Grosso. Dourados, MS: Embrapa Agropecuária Oeste, Campina Grande, PB: Embrapa Algodão.

Leite, L. A. I., \& Nuss, A. (2017). Prejuízos decorrentes de perdas na colheita do algodão com diferentes tipos de colhedoras. Revista de Agricultura Neotropical, 4(4), 70-76. https://doi.org/10.32404/rean.v4i4.1669

Lima, R. W., Araújo, W. P., Pereira, J. R., Cordão, M. A., Ferreira, F. N., \& Zonta, J. H. (2018). Fibras de algodoeiro herbáceo sob déficit hídrico. Revista Verde de Agroecologia e Desenvolvimento Sustentável, 13(4), 427-436. http://dx.doi.org/10.18378/rvads.v13i4.5940

Lima, J. J., \& Bélot, J. L. (2015). A fibra de algodão: qualidade e classificação. In Bélot, J. L., Manual de boas práticas de manejo do algodoeiro em Mato Grosso (p. 280-295). IMAmt, AMPA.

Mion, R. L., Bélot, J. L., Dutra, S. G., \& Bassini, R. T. (2014). Preservação da qualidade da fibra: recomendações para o manejo da umidade durante a colheita. IMAmt, Nota técnica, 3 .

Morello, C. L., Pedrosa, M. B., Suassuna, N. D., Farias, F. J. C., Silva Filho, J. L., Perina, F. J., Freire, E. C., Alencar, A. R., Tavare, S, J. A., \& Oliveira, W. P. (2015). Desempenho de Cultivares de Algodoeiro no Cerrado do Estado da Bahia, Safra 2013/2014. Campina Grande: Embrapa Algodão. Documento, 253.

Pereira A. S. et al. (2018). Metodologia da pesquisa científica. UFSM. 5.3)

Ribas, P. V. (2014). Colheita do algodão, armazenagem e transporte. In Chanselme, J. L., Manual de beneficiamento do algodão. (p. 29-49). IMAmt.

Santana, J. C. F., Wanderley, M. J. R., Beltrão, N. E. M., Azevedo, D. M. P., Leão, A. B., \& Vieira, D. J. (2008). Características da fibra e do fio do algodão: análise e interpretação dos resultados. In: Beltrão, N. E. M., Azevedo, D. M. P. O agronegócio do algodão no Brasil. Embrapa Informação Tecnológica 2.

Santana, J. C. F., Santana, J. C. S., \& Beltrão, N. E. M. (2004). Fibras do algodão. In Algodão: 500 perguntas / 500 respostas. (p. 213-219) Embrapa algodão. from https://mais500p500r.sct.embrapa.br/view/pdfs/90000001-ebook-pdf.pdf

Santos, S. R., Soares, A. A., Kondo, M. K., Matos, A. T., \& Maia, V. M. (2016). Indicadores de produção e qualidade da fibra do algodoeiro fertirrigado com água residuária sanitária. Engenharia Agrícola, 36(3), 525-536. http://dx.doi.org/10.1590/1809-4430-Eng.Agric.v36n3p525-536/2016

Silva, A. E. F., Procópio, D. P., Cardoso, H. Q., Gozzi, G., \& Dambrós, F. S. (2019). Análise comparativa da cotonicultura no estado de Mato Grosso. Research, Society and Development, 9(3), 01-19. https://doi.org/10.33448/rsd-v9i3.2313

Silva, R. P., Ferreira, I. C., \& Cassia, M. T. (2011). Perdas na colheita mecanizada de algodão. Scientia Agropecuaria. 2(1), 07-12. https://doi.org/10.17268/sci.agropecu.2011.01.01

Silva Filho, J. L., Pedrosa, M. B., Suassuna, N. D., Morello, C. L., Farias, F. J. C., \& Perina, F. J. (2017). Avaliação de cultivares de algodoeiro no Cerrado da Bahia, safra 2015/2016. Embrapa Algodão (Documentos, 269).

TMG, Cultivares: TMG 81 WS, 2016. https://www.tmg.agr.br/ptbr/cultivar/tmg-81-ws

Vasconcelos, W. S. (2016). Análise genética para caracteres de fibras em genótipos de algodoeiro submetidos a estresse hídrico. Dissertação (Mestrado em Ciências Agrárias) - UFGC/PB.

Vilela, P. M. C. A., \& Bélot, J. L. (2015). Variedades comerciais e pré-comerciais de algodão para o Mato Grosso. Resultados agronômicos e de tecnologia de fibra da rede de difusão de cultivares e de ensaios do IMAmt -Safra 2014/15. Instituto Mato-Grossense do Algodão, Circular Técnica, 22.

Viotto, G. F. V., Vale, W. G., Silva Júnior, A. N., Ruffato S., \& Gravina, G. A. (2018). Avaliação das perdas na colheita do algodão em diferentes velocidades. Scientific Electronic Archives. 11(4), 48-55. https://doi.org/10.36560/1142018543 